\title{
Post-neoliberalismo, Post-pandemia Covid-19 y sociedad civil global
}

\author{
kmt07145@ir.ritsumei.ac.jp
}

Relaciones Internacionales

https://revistas.unlp.edu.ar/RRII-IRI Vol 30 - no 60/2021

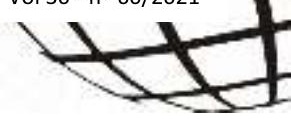

\author{
Kiyoshi Matsushita
}

\author{
Kiyoshi Matsushita
}

Recibido: 26/05/2021

Ritsumeikan University (Kyoto, Japón)
Aceptado: 19/06/2021

Resumen: La globalización neoliberal impulsa los procesos sociales, económicos, culturales
e ideológicos en todo el mundo en el siglo XXI, lo que precede a la división de cada nación,
comunidad, región y el patrón de pensamiento, incluida la construcción de muros, un gran
número de refugiados y emigraciones, y muchos conflictos y actividades terroristas.
Según el informe de Oxfam de 2019 , se crea un nuevo multimillonario cada dos días y las
26 personas más ricas del mundo poseen tanto como el $50 \%$ más pobre. Al aumentar esta
polarización y desigualdad, la globalización neoliberal alimentó el problema crónico de la
sobreacumulación y la militarización.
Este artículo se centra en el presente de la globalización neoliberal bajo la pandemia del
Covid-19. Significa una reconsideración crítica del capitalismo moderno que trae ahora una
profunda miseria a la historia de la humanidad, lo que incluiye la pobreza, los refugiados,
la inmigración, los crímenes transnacionales, el cambio climático y la pandemia. Además,
se violan los derechos humanos fundamentales como consecuencia del control supremo
del mercado, la competencia y la desregulación por parte de las empresas multinacionales.

Palabras clave: post-neoliberalismo, pandemia post-Covid-19, sociedad civil global, movimientos anticapitalistas, gobernanza democrática de múltiples capas

* Cómo citar este artículo: Matsushita, K. (2021). Post-Neoliberalismo, Post-Pandemia Covid-19 y Sociedad Civil Global. Relaciones Internacionales, 30(60), 128. https://doi.org/10.24215/23142766e128

Editor: Juan Alberto Rial, Instituto de Relaciones Internacionales Facultad de Ciencias Jurídicas y Sociales (Universidad Nacional de La Plata)
Entidad editora: Relaciones

Internacionales, es una publicación del Instituto de Relaciones Internacionales (Facultad de Ciencias Jurídicas y Sociales (Universidad Nacional de La Plata Argentina)

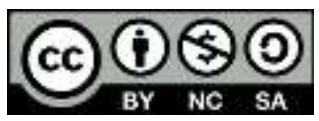

Reconocimiento-NoComercial Compartirlgual 4.0 Internacional (CC BY-NC-SA 4.0) 


\title{
Post-neoliberalism, post-Covid-19 pandemic and global civil society
}

\section{Kiyoshi Matsushita ${ }^{1}$}

\begin{abstract}
The neoliberal globalization drives the social, economic, cultural, and ideological worldwide processes in the 21st century, which takes precedence to the division of each nation, community, region, and the pattern of thinking, including the constructions of walls, huge numbers of refugee and emigrations, and many conflict and terrorist activities.

According to a 2019 Oxfam's report, a new billionaire is created every two days and the world's 26 richest people own as much as the poorest 50 percent. By making this polarization and inequality escalate, neoliberal globalization has fueled the chronic problem of overaccumulation and militarization.

This article focuses on the present of neoliberal globalization under the Covid-19 pandemic. It entails a critical reconsideration of modern capitalism, which now brings deep misery to human history, including poverty, refugees, immigration, transnational crimes, climate change and pandemic. Furthermore, fundamental human rights are violated as a consequence of the utter control of the market, competition, and deregulation by multinational companies.
\end{abstract}

Key words: post-neoliberalism, post-Covid-19 Pandemic, global civil society, anti-capitalist movements, multilayered democratic governance

1 Doctor en Relaciones Internacionales, Profesor emérito de la Ritsumeikan University, Kyoto, Japón. La traducción del artículo fue realizada por Máyuko Kawai. 


\section{Introducción}

La pandemia ha puesto en evidencia la inevitable conexión que existe entre el destino de las comunidades sobre nuestro planeta y el de la humanidad en su totalidad. Esta situación es considerada como la crisis más grande desde la Segunda Guerra Mundial. El colapso económico ocasionado por el coronavirus ha evidenciado cuán subordinados estamos todos nosotros a la producción, a las finanzas y al sistema de servicio globalmente integrados y cuán controlados estamos por la clase hegemónica multinacional y los agentes políticos de los estados capitalistas mundiales.

La humanidad sufre varias situaciones difíciles, desde la crisis del sistema ecológico hasta la guerra, pobreza, desigualdad, enfermedad y refugiados, entre otros. Si hay esperanzas de que exista una solución para estos problemas lamentables, ella es enfrentar colectivamente, más allá de las fronteras nacionales, al sistema capitalista mundial y a los poderes que dominan nuestros medios de existencia. El coronavirus también ha expuesto estos problemas.

Ahora bien, ¿̇las élites y las organizaciones dominantes del sistema mundial actual están llegando a sus límites o están en el proceso de llegar a su fin? Desde la ineptitud del ex presidente norteamericano, Donald Trump, en cuanto a las medidas contra la pandemia y los dispositivos asistenciales en dólares multibillonarios hasta la caída repentina de la economía global, miles de millones de trabajadores en inestabilidad enfrentan amenazas a sus vidas. Se ha visto, además, el colapso del sistema de la seguridad pública por la reducción en gran escala de sus fondos. La pandemia ha revelado la incapacidad de las élites y las organizaciones dominantes de resolver esta crisis de la humanidad.

Cientos de millones de refugiados multinacionales vienen enfrentando el virus sin poder tener acceso a la salud. Las medidas asistenciales contra el virus ignoran a los presos en hacinamiento, a las personas sin hogar y a aquellos en regiones en guerra.

Actualmente bajo estas circunstancias, se encuentra en expansión en cierto espacio de prensa e imprenta un discurso tal como el fin del capitalismo, la crisis de la historia y la crisis de la humanidad. En cuanto al nivel global, por ejemplo, no sólo está empeorando el medioambiente de la vida de las personas (alimentos, violencia y crimen, migración, refugiados, pobreza y hambre, desempleo, etc.), sino también está a punto de caer en la crisis el medioambiente que rodea la humanidad (calentamiento global, contaminación marítima, diversidad de las especies, etc.).

Exclusión e inclusión son las prácticas forzadas, tanto política y económica como socialmente. Esta relación de exclusión e inclusión es política económica, financiera e ideológica y gira alrededor del eje de la división. Por un lado, se publicitan el nacionalismo xenófobo, racismo, particularismo y populismo y, por otro lado, se busca y consigue el rápido desarrollo de tecnologías digitales, especialmente de la renovación de información y tecnología e inteligencia artificial, así como también la integración dirigida por organismos financieros y la integración regional promovida por empresas multinacionales. Las situaciones que rodean el mundo son las consecuencias de la globalización desenfrenada e impulsada por neoliberalismo. Es a raíz de esto que llama atención como tarea urgente la 
realización de Objetivos y Metas de Desarrollo Sostenible de las Naciones Unidas.

Este artículo tiene como objetivo analizar la forma en que las personas en la era de Antropoceno reconocen el presente y cómo lo problematizan, y explorar su posibilidad tanto de enfrentar la globalización neoliberal y el mundo post-Covid-19 como de lograr la solidaridad ciudadana global y democrática y una construcción social que trasciendan las ideas centradas en el estado.

\section{La era del Fin del Neoliberalismo}

\section{Límite de la globalización neoliberal}

En sentido comparativamente amplio, el neoliberalismo es conceptualizado como la última fase de la dominación estructural y hegemónica global. Por ejemplo, de acuerdo con Stephen Gill, el neoliberalismo es una nueva era, que sostiene la reestructuración de la relación entre estado nación y organismos transnacionales. Este sistema disciplinario formativo global está relacionado con el desarrollo inevitable de la civilización del mercado y la jerarquía social (Gill, 1995).

Es en esta era que la presente pandemia Covid-19 está amenazando a la humanidad. Esta pandemia, además de ser una crisis sanitaria, es una crisis política, ideológica y educacional. Es también una crisis de diferentes valores democráticos y de la destrucción de la educación y medioambiente, ligada a la crisis de desigualdad en gran escala de riqueza, ingresos y poder. Es decir, es una crisis de la sociedad entera, donde la política en general está instrumentalizada por el neoliberalismo.

Wendy Brown visualiza de la siguiente manera la penetración y crecimiento del discurso neoliberal y observa la crisis de la sociedad entera o del sistema: El neoliberalismo está desmoronando silenciosamente los elementos fundamentales de la democracia. Están incluidos en estos elementos los "términos principios de justicia", "culturas políticas", "hábitos de ciudadanía", "prácticas de dominio" y, sobre todo, "imaginarios democráticos". Brown resalta su propósito sin ambigüedad, de la siguiente manera:

Mi argumento no sólo es que los mercados y la moneda corrompen y deterioran la democracia, sino también que las instituciones políticas y sus consecuencias son cada vez más dominadas por el capital financiero y empresarial. La democracia está siendo reemplazada por plutocracia - la dominación por y para los adinerados. Además, la razón neoliberal, hoy omnipresente en políticas, lugares de trabajo, jurisprudencia, educación, cultura y en un vasto espacio de actividades cotidianas, está convirtiendo en lo económico, la característica, el significado y la operación distintivamente políticos, que son los componentes fundamentales de la democracia. Tal vez las instituciones, prácticas y hábitos democráticos liberales no 
sobrevivan esta conversión. Tampoco quizás los sueños democráticos radicales (Brown, 2015: 17) ${ }^{2}$.

\section{Expulsión de la seguridad del ser humano}

El Sur Global es un concepto correspondiente a la nueva fase del capitalismo neoliberal de la Posguerra Fría con características únicas. Estas características incluyen la expansión sin precedentes de las corporaciones multinacionales, su poder y su cadena de producción global. Las consecuencias de estas políticas son conocidas. Hay concentración extrema de la riqueza a nivel global y nacional, y la brecha es mayor entre el estrato extremadamente rico y la mayoría de la población. La privatización de los bienes comunes salud, agua, transporte, energía, conocimiento, semillas, etc.- ha agrandado el poder de los sectores privados. Más aún, la realidad reciente que merece atención es el hecho de que los sitios pobres existen tanto en el sur como considerablemente también en el norte. Al mismo tiempo, muchas zonas acaudaladas donde las élites nacionales acumulan la riqueza también existen en el sur. Con la globalización han aparecido diferentes formas de una nueva jerarquía social y desigualdad que se organizan y proliferan más allá de las fronteras nacionales.

\section{Capitalismo global y acumulación excesiva}

William Robinson analiza política y estructuralmente la vulnerabilidad de la economía global frente al coronavirus (Robinson, 2020a; 2020b; 2020c; 2020d). El coronavirus ha puesto en caos a las redes globales de oferta y diseminado el pánico a través del mercado mundial de acciones. La pandemia sigue en expansión, causando grandes daños. Sin embargo, desde el punto de vista más amplio, las consecuencias del virus han revelado la vulnerabilidad de la economía global. Esta vulnerabilidad no se ha recuperado suficientemente desde el colapso financiero de 2008 , y ha venido sacudiendo por años y generando nuevas crisis.

La crisis del capitalismo global es tanto política como estructural. Políticamente, este sistema se enfrenta a la crisis de la hegemonía del capitalismo y de la legitimidad del estado. La división social y desigualdad a nivel global no tiene precedentes. En el 2018, el $1 \%$ del estrato superior de la humanidad controlaba más de la mitad de la riqueza mundial, mientras que el $80 \%$ del estrato inferior se veía obligado a contentarse con el $4.5 \%$ de ella. Si bien este tipo de desigualdad global aguda facilita la explosión política, la dificultad del sistema para revertir la desigualdad hace que éste conduzca a una forma violenta de acorralamiento para administrar a la población empobrecida.

Estructuralmente este sistema se encuentra ante la crisis conocida como acumulación excesiva. A medida que se incrementa la desigualdad, el sistema genera una riqueza cada vez mayor que la que la vasta población trabajadora realmente puede consumir. En consecuencia, el mercado global no puede absorber el producto de la economía global. La acumulación excesiva está relacionada con las situaciones en las cuales se acumula el gran

\footnotetext{
${ }^{2}$ Todas las traducciones son propias.
} 
capital (utilidad). Sin embargo, este capital se estanca sin poder ser útilmente reinvertido.

Efectivamente, las empresas obtuvieron utilidades récord en la década de 2010, en la cual también disminuyó la inversión empresarial. La reserva corporativa a nivel mundial sobrepasó los 12 billones de dólares en 2017, lo cual es mayor que la reserva de divisas de los principales países del mundo. Las corporaciones multinacionales no pueden, empero, encontrar suficientes oportunidades para reinvertir útilmente esa ganancia. A medida que se acumula este capital que no puede ser invertido, aumenta la gran presión que requiere una salida para disponer del excedente. Para el siglo XXI, la clase capitalista transnacional enfrentará la acumulación del excedente y recurrirá a algunos mecanismos para mantener la acumulación, especialmente la malversación del financiamiento público, el crecimiento impulsado por la deuda, la acumulación militar dirigida por el estado y la especulación financiera en casinos globales, entre otros (Robinson, 2020b).

\section{Neoliberalismo, coronavirus y politización del orden natural}

Como señala Naomi Klein, mucho antes de la presente crisis de la pandemia, los promotores del neoliberalismo habían intentado escatimar en servicios, tales como asistencia médica a expensas del estado, agua limpia, buenas escuelas públicas, lugares seguros de trabajo, pensiones y otros programas asistenciales para adultos mayores y personas desfavorecidas. Al mismo tiempo, la misma idea de la esfera pública y el bien público fue atacada por el capitalismo depredador. Como una de sus consecuencias, están arruinadas las infraestructuras básicas, como carreteras, puentes, diques y sistema de agua, que son propiedades públicas de una sociedad (Klein, 2017).

Henry A. Giroux, en su texto "La pandemia Covid-19 está exponiendo la plaga del Neoliberalismo" (The Covid-19 Pandemic Is Exposing the Plague of Neoliberalism), presenta una observación perspicaz sobre la relación entre la pandemia Covid-19 y la epidemia del neoliberalismo y advierte la crisis de la sociedad entera causada por el neoliberalismo capitalista (Giroux, 2021). Estamos en el momento en el cual podemos darnos cuenta de que el neoliberalismo es una máquina que produce no sólo la desigualdad a gran escala y el sufrimiento del ser humano, sino también la muerte cruel que avanza un paso más hacia la crisis de la extinción de la humanidad.

La presente pandemia del coronavirus es una crisis estructural profundamente arraigada en los gobiernos neoliberales, que negaron la importancia de la salud pública y el bien público, y que han venido absorbiendo el capital de los sistemas que habían posibilitado dichos servicios públicos.

La pandemia del coronavirus está ligada a fondo con la politización del orden natural a través del ataque destructivo, explayado por la globalización del neoliberalismo, contra el ecosistema. Además, esto no se puede separar de la discriminación racial, el supernacionalismo, los sentimientos anti-inmigrantes y los actos intolerantes.

A fin de promover las políticas de despolitización, el neoliberalismo da importancia al rol principal de la educación. Por ejemplo, de acuerdo a los principios educativos centrales del neoliberalismo, la responsabilidad individual es la única forma de tratar los problemas sociales $y$, por ende, no es necesario tomar medidas para resolverlos como problemas 
integrales ni exigirle al poder la toma de la responsabilidad de explicarlos y/o admitir esos problemas causados por la responsabilidad colectiva. El neoliberalismo privatiza e individualiza los problemas sociales como políticas de contención y, de esa manera, intenta acorralar las políticas democráticas verdaderas.

Giroux señala sagazmente el peligro de que el neoliberalismo fermente una crisis cultural por medio de la ideología fascista. Este autor entiende el resultado de ello como crisis de la sociedad en su totalidad. Esta es una era caracterizada por el desprecio a la debilidad, la proliferación de la discriminación racial, el ascenso de la emoción sobre la razón, el colapso de la cultura cívica, y la obsesión por la riqueza y los intereses personales. Bajo estas circunstancias, nos estamos enfrentando no simplemente a una crisis política, sino también educativa. Esta es una política en la cual los mecanismos políticos y culturales se ven instigados por los organismos que hacen perder las fuerzas imaginativas de la verdad, la justicia y la ética.

Para poner fin a esta epidemia, es necesario enfrentarnos con la ideología fascista neoliberal y desarrollar una reflexión amplia que abarca más allá de la sociedad de consumidores y la cultura de privatización. Es indispensable generar movimientos de resistencia por una sociedad más justa e igualitaria.

David Harvey argumenta que lo fundamental es que actualmente los movimientos anticapitalistas son las únicas opciones. La gravedad de la crisis actual ofrece la nueva posibilidad de que las personas comiencen a reflexionar sobre cómo es la sociedad, el mundo y el futuro en el cual les gustaría vivir. Esto no es volver al sistema que identifica la democracia con el capitalismo. La presente crisis tiene raíces políticas y económicas más profundas y demanda una reconstrucción integral de la sociedad (Harvey, 2020). Mientras que Harvey lo enfatiza así, Giroux también concluye que la resistencia al neoliberalismo predatorio es la tarea urgente.

Aún tenemos la oportunidad de reimaginar un mundo en el que el futuro no se asemeja al presente neoliberal predatorio. Este debe ser un mundo que reúna las luchas por justicia, emancipación e igualdad social. Lo que es más urgente de todo es la necesidad de luchar por un mundo que imagina y actúa en base a las promesas utópicas de una justicia y a la sociedad socialista democrática. Frente a la pandemia Covid-19, los asuntos de crítica, entendimiento y resistencia son elevados a una cuestión de vida o muerte. La resistencia es una necesidad extremadamente urgente (Giroux, 2020).

\section{Profundización de las divisiones}

En los Estados Unidos la desigualdad de ingreso está en aumento. Es importante que se reconozca que tanto los estratos más bajos del ingreso como la reducción de los estratos medios constituyen la base conservadora y racista de la integración y la exclusión del poder político de Trump. Semejante situación se observa también en la zona del euro, en Grecia, España, Portugal y en otros países desarrollados. El deterioro del nivel de la vida social y económica de los ciudadanos ha puesto a flote los fenómenos políticos como el populismo. La entrada en plena escala del neoliberalismo en la década de los 80 , el colap- 
so de la Guerra Fría y la globalización transformaron enormemente la organización social integral previamente existente bajo el keynesianismo y el fordismo. Desde entonces, la globalización ha venido promoviendo el proceso de polarización desigual, y de inclusión e integración selectivas, ligado a la separación y la división del mundo.

Esta división se convierte en caldo de cultivo que genera diversas violencias. Algunos países en desarrollo se encuentran ante la violencia estructural, por ejemplo con el terrorismo, trata de personas, tala ilegal, drogas ilegales, exportación de armas, crimen cibernético y lavado de dinero, entre otros, producida por el neoliberalismo. En este momento de la pandemia, la división tiende a acelerar la exclusión y la expulsión de la era neoliberal.

El término "división" implica varias cosas: discriminación diversa y extensa, explotación y saqueo, diferencias económicas y educacionales, acceso a los derechos ciudadanos y a las necesidades básicas, fronteras y obstáculos, el sistema de castas y apartheid, refugiados e inmigrantes, entre otros. Dicho esto, es necesario prestar atención a que la división lleva consigo un proceso especial de exclusión y marginalización.

Ahora bien, quisiera enfocarme la teoría de la expulsión sostenida por Saskia Sassen (Sassen, 2014). Sassen indica que manejar el concepto de expulsión significa traspasar una de las formas de comprender la patología del capitalismo global, como puede ser el concepto de la desigualdad creciente. En este sentido, la expulsión parece apropiada como un concepto que capta integralmente la patología crítica profunda y severa del capitalismo global. La expulsión, que traspasa la discriminación, está siendo impuesta a las personas como refugiados e inmigrantes forzados, a aquellos en los establecimientos de detención y prisión, a las víctimas de la pandemia y de los crímenes de odio, etc., los cuales examinaré más adelante.

Una cuestión que traza la investigación de Sassen respecto al concepto de la expulsión es si la mezcla de casos que atraviesan las divisiones conocidas de lo urbano versus lo rural, el Norte Global versus el Sur Global, este y oeste, etc., es la manifestación superficial y la figura localizada de dinámicos sistémicos que articulan mucho de lo que ahora aparentan como desconectados (Sassen, 2014: 5).

\section{El mundo divergente: policialización de los Estados}

\section{El fracaso de la marea rosa}

La influencia determinante del neoliberalismo en América Latina, que ha penetrado en todos los territorios y sectores, hace que el estudio de la región contemporánea presuponga el análisis de dicha influencia. Casi todos los fenómenos sociales se han venido manifestando por medio de las políticas neoliberales. La vida del pueblo ha sido sacudida por la pobreza, las diferencias, la inmigración, el cártel de la droga y la violencia, los movimientos indígenas y la destrucción de sus comunidades, y la explotación excesiva de sus recursos, entre otros. Es preciso indagar el surgimiento de los gobiernos izquierdistas en el fondo de las circunstancias mencionadas. Al mismo tiempo, hay que averiguar con toda seriedad las causas de su fracaso (Weyland, Madrid, and Hunter eds., 2010; Sader, 2011). 
La continuación arraigada del neoliberalismo en los procesos políticos y sociales dinámicos de América Latina ha traído como resultado la profundización de la privatización de la sociedad entera en forma extrema. Una manifestación concreta de ello es la privatización de los asuntos migratorios, de refugiados y de las cárceles.

\section{Inmigración, refugiados y la privatización de las cárceles}

Los pobres, los inmigrantes, los refugiados racialmente oprimidos y aquellos en las sociedades vulnerables son excluidos y se han convertido en objeto de crímenes. Esto es también la acumulación más evidente de la opresión. Este tipo de criminalización activa la opresión legítima del estado, que coacciona la acumulación del capital. De esta manera, el estado ha promovido el capital privado para que ejecute la opresión sobre las personas incriminadas. El encarcelamiento iniciado por los Estados Unidos rápidamente se expandió a todo el mundo. Estados Unidos ha venido exportando el sistema de encarcelamiento a gran escala. En el 2019, se vinculó a dicho país con el sistema penitenciario de, por lo menos, 33 países. Por otro lado, la población penitenciaria a nivel mundial aumentó un $24 \%$ entre los años 2000 y 2018.

A inicios del siglo XXI, existían a nivel mundial aproximadamente 200 cárceles privadas y muchas asociaciones público-privadas relacionadas a las cárceles. Esto incluye servicios penitenciarios privados, de protección y de monitoreo que buscan ganancias, como programas privados digitales de monitoreo.

En personas así incriminadas están incluidos millones de inmigrantes y refugiados de todo el mundo. Estos en todas las fases han sido las fuentes de la formación de utilidad para el capital transnacional. En el 2010 hubo 270 cárceles migratorias en los Estados Unidos. Entre el 2010 y el 2018, los egresos federales para la detención saltaron de 1,800 millones a 3,100 millones de dólares. En los Estados Unidos se pronosticaba que la industria de la seguridad de fronteras duplicaría su utilidad de 305 mil millones de dólares en el 2011 a 740 mil millones de dólares en el 2023.

Juan Manuel Sandoval, investigador mexicano, hace el seguimiento de cómo las zonas fronterizas entre los Estados Unidos y México han sido reconstruidas como espacio global para la expansión del capital transnacional. Se observa en este espacio global, la concentración en el lado estadounidense de las industrias militares de alta tecnología, aquellas relacionadas a las aeroespaciales y las bases militares. Se desarrollan allí las influencias civiles y militares que luchan contra "la inmigración, el tráfico de drogas, y el terrorismo a través de una estrategia de guerra de baja intensidad" (Sandoval, 2017).

A medida que aumenta la detención y persecución, las empresas tecnológicas hegemónicas de los Estados Unidos juegan un rol principal también en esta área, involucrándose considerablemente en la guerra contra los inmigrantes. Igualmente han venido cabildeando para que el estado utilice el control social y la tecnología de vigilancia progresista (Robinson, 2020: 96 -97).

\section{Nueva industria global: empresas contratistas militares y de seguridad}

Las guerras, los conflictos, los controles y las opresiones en el mundo expanden y 
promueven las oportunidades de la acumulación del capital privado a través de la militarización de los gobiernos, es decir, la fusión de la acumulación privada con la militarización estatal. Esto implica fomentar la venta global de armas por parte de las empresas militares, industriales y de seguridad (Robinson, 2020b).

En el momento de la cúspide de las guerras en Irak y Afganistán, el número de empresas militares contratistas privadas en ambos países superó el de los combatientes del gobierno americano. El despliegue a escala mundial de las empresas militares y de seguridad privadas va más allá de los Estados Unidos y no se limita a las principales regiones en conflicto de Medio Oriente, Asia del Sur y África.

P. W. Singer se refirió a la importancia del rol cada vez más principal de las firmas militares privadas (PMFs) en los conflictos militares y las guerras como "la aparición de una nueva industria global" (Singer, 2003). Es el cambio de forma del contrato y la privatización en el siglo XXI que está transformando las reglas convencionales de las políticas internacionales y de la guerra. Su globalización es cada vez mayor tanto en extensión como en actividad. Las PMFs son de diferentes países del mundo, como Rusia, Sudáfrica, Colombia, México, India, los de la Unión Europea y sobre todo Israel.

La clientela de PMFs está constituida por estados, empresas, terratenientes, organizaciones no gubernamentales y hasta cárteles de la droga en Colombia y México. Entre el 2005 y 2010, el Pentágono firmó contratos con aproximadamente 150 empresas de todo el mundo para asistencias y actividades de seguridad en Irak. Para el 2018, las firmas militares privadas emplearon unos 15 millones de personas a nivel mundial. Con el propósito de proteger el capital empresarial, despliegan las influencias: proveen personal para el consejo directivo empresarial y sus familiares, recolectan datos, ejecutan el control y la opresión de los opositores a través de las policías, las organizaciones paramilitares, la represión de las guerrillas y las actividades de vigilancia. Además de ello, administran las cárceles y dirigen las instituciones privadas de detención y de interrogación. Todo ello es precisamente la participación en la guerra total.

Por otro lado, el negocio de la seguridad privada (orden público y vigilancia) es uno de los sectores económicos que ha crecido con mayor rapidez en muchos países, y proyecta su sombra sobre la seguridad del Estado en el mundo. En el 2003, el año en que ocurrió la invasión en Irak, el monto total gastado por la seguridad privada fue $73 \%$ mayor que el gastado por los sectores públicos (Robinson, 2020: 79 - 80).

\section{Redes y actividades del complejo carcelario-industrial}

El complejo carcelario-industrial es utilizado para mantener el poder del Estado, fortalecer la jerarquía social establecida y describir lo complejo del sistema e instituciones que actúan en colaboración para concentrar la riqueza. Esto incluye, entre otras cosas, la criminalización, la vigilancia, el orden público y custodia, los medios de comunicación, el tribunal de justicia y las cárceles.

Como se ha mencionado antes, la expansión de la privatización de la cárcel es rápida. Desde 1980, la población carcelaria de los Estados Unidos ha incrementado un 355\%. Hoy es el país que encarcela más personas que cualquier país del mundo, cuyo número equiva- 
le a una cuarta parte de la población encarcelada de todo el mundo. La responsabilidad del sistema de las instituciones carcelarias y de detención de los Estados Unidos está cedida a las firmas privadas que persiguen fines de lucro. La privatización de la cárcel se presenta en diversas formas: los establecimientos poseídos y administrados enteramente por las firmas privadas, aquellos que son propiedad del gobierno y están administradas por las empresas, las instituciones públicas que consignan ciertos servicios (como construcción y alimentos), etc. (Arabella Advisors, 2018).

El complejo carcelario-industrial es una red extensa de miles de empresas públicas y privadas, muchas de las cuales han obtenido utilidades directamente de innumerables personas que fueron detenidas en los Estados Unidos desde 1980 en adelante. Entre las empresas que se benefician del sistema carcelario están los nombres de los administradores de las cárceles privadas, como el Grupo GEO (antiguamente The Wackenhut Corrections Corporation) y Core Civic. Estos administradores ofrecen prisiones privadas, celdas, centros de detención migratorios, programas comunitarios de correccionales, industria de la fianza con fines de lucro y otras instalaciones relacionadas a la detención. Se incluyen también las empresas que ofrecen los bienes y servicios a aquellas que se benefician a través del uso de trabajadores encarcelados.

Adicionalmente a la privatización de cárceles, los centros de detención, los correccionales para menores, los centros de rehabilitación, los programas digitales de vigilancia y los servicios en las cárceles, muchas empresas transnacionales están instalando fábricas dentro de las cárceles (Sassen, 2017: 89 - 97).

Las corporaciones privadas pueden beneficiarse de los trabajos con bajo salario en algunas formas:

1. A partir del uso directo de la mano de obra de los prisioneros para trabajos de manufactura y servicios.

2. A través de la contratación con otras empresas para comprar productos o servicios hechos por prisioneros.

3. Con la inversión en las empresas carcelarias privadas responsables de expandir constantemente el sistema global de corrección (Sassen, 2014: 74).

Muchas empresas, como Chevron, Bank of America, AT\&T, Starbucks, Walmart, etc., que se benefician de las labores en las cárceles, lo hacen a través de la segunda de las tres formas mencionadas.

\section{El resurgimiento de la hegemonía autoritaria y derechista}

La guerra contra la droga conecta la economía oficial del capitalismo global con la informal, que incluye la economía criminalística. El capitalismo siempre tuvo la cara de Jano. El revés de las actividades honestas, legales y legítimas es la economía en negro o subterránea, ilegal e ilegítima. Las dos caras están integradas de manera funcional (Robinson, 2020: 102). 
El comercio violento de la droga es, en sí, la forma de acumulación del capital global militarizado. Desde la década de los 90, Estados Unidos ha venido invirtiendo decenas de miles de millones de dólares en la guerra contra la droga de América Latina. Esta inversión ha abierto las oportunidades de acumulación en diversos niveles. En nombre de la guerra contra el tráfico ilícito de drogas, las actividades del ejército y de la policía han provocado la exclusión de los pobres locales, de los indígenas, de los descendientes afroamericanos y de otras comunidades del campo en Colombia, Centro América y México. De tal manera, las tierras fueron saqueadas por terratenientes locales y capitalistas multinacionales. La exclusión de los habitantes como estrategia de la guerra tiene como objetivo "la obstrucción de las actividades colectivas, destrucción de las redes sociales y la amenaza y el control de los ciudadanos. Quitando al pueblo de la tierra, se abren nuevos territorios para la llamada inversión de frontera" (Paley, 2014).

Estas actividades proveen la mano de obra estable para la agroindustria, la minería, y otras actividades extractivas que se han expandido a través de la globalización capitalista, la cual sirve como cortina de humo para suprimir los movimientos sociales. Especialmente es así en el caso de aquellas actividades dirigidas en contra de las protestas en Colombia. A final de cuentas, la enorme cantidad de dinero es convertida en recursos para las empresas multinacionales. Por ejemplo, el gobierno estadounidense asignó, entre 2008 y 2015 , 2.500 millones de dólares al Plan México (Robinson, 2020: 103).

Hoy, de esta manera, América Latina está atravesando condiciones peligrosas en las cuales se fusionan la violencia del estado y la violencia privada. En estas regiones avanza la apertura para reprimir las rebeliones políticas y promover los saqueos empresariales, convirtiéndose en el espejo para otras regiones del mundo.

\section{El confinamiento opresivo y la consolidación de la vigilancia}

Durante la pandemia, muchas personas se vieron obligadas a confinarse en sus casas, lo cual no fue fácil. El confinamiento opresivo significa para un gran número de personas enfrentarse al hambre. No pueden buscar los víveres y realizar las actividades de sobrevivencia sin sufrir la represión militar o policial. Las personas que ocuparon las calles en busca de asistencia han sido víctimas de balas, bombas lacrimógenas y arresto. Se han reportado casos de la violación de los derechos humanos, represión de opositores, consolidación de la vigilancia y control de los medios de comunicación (Robinson, 2020e).

En Rusia, apenas declarada por el gobierno la falsedad de información sobre el virus, se les exigieron a los medios de comunicación la suspensión de su publicación. Los gobiernos de Turquía, Montenegro y Serbia arrestaron y multaron a las personas que publicaron la información en redes sociales por causar pánico y exponer el orden público al peligro. Para estimar cuánto obedecen los ciudadanos el confinamiento, los gobiernos de Italia, Alemania, China y Austria instalaron un sistema para analizar datos de teléfonos celulares en colaboración con las grandes empresas de alta tecnología. En Filipinas, el presidente autoritario Duterte ordenó disparar a aquellos que incumplan el confinamiento.

En India, el gobierno declaró el estado de emergencia y coactivamente encerró a su población en sus casas. Sin embargo, cientos de millones de trabajadores informales que pasan hambre si no salen a la calle han sufrido la violencia cruel y afrentosa de las policías. 
Tales escenas fueron captadas por las cámaras de televisión y redes sociales, tal como han sido difundidas en todo el mundo. Decenas de miles de trabajadores inmigrantes han sido atrapados por el confinamiento en regiones lejanas de sus propios pueblos. La cancelación de los medios de transportes públicos los obligó a marchar cientos de kilómetros para volver a sus casas, resistiendo a la represión del estado.

El gobierno dictatorial de Honduras ordenó el confinamiento a nivel nacional, ejecutado por el ejército y la policía. Fueron suspendidas varias garantías constitucionales, como libertad de expresión, de movimiento y de detenciones arbitrarias. En los primeros días fueron arrestados cientos de personas, entre las cuales estaban los opositores políticos. La prohibición de los mercados callejeros y ambulantes ha llevado consigo cuestiones de importancia vital para la totalidad del pueblo hondureño. El $60 \%$ de los hondureños vive en pobreza y el $70 \%$ son empleados en sectores informales.

De este modo y por el confinamiento represivo, millones de personas en el Sur Global se han enfrentado al hambre sin poder salir en busca de alimentos ni pedir ayuda. Las situaciones críticas en torno a la expansión del virus agudizaron considerablemente la sociedad de vigilancia discutida por David Lyon (Lyon, 2002) y se podría decir que se convirtieron en conejillo de Indias del capitalismo de vigilancia.

\section{Hacia el orden mundial post-Covid-19}

\section{Ruptura con la ideología neoliberal}

El discurso neoliberal se ha vuelto hegemónico y "tiene efectos penetrantes sobre formas de pensar a tal punto que se han incorporado en la manera del sentido común en la cual muchos de nosotros interpretamos, vivimos y entendemos el mundo" (Harvey, 2005: 3). He allí la dificultad de resistir al neoliberalismo y recuperar la vida y la democracia. Igualmente, el neoliberalismo inserta sus influencias en diversos territorios, desde el lugar de la educación, las políticas económicas y financieras, hasta los organismos importantes estatales e internacionales.

Brown enfatiza el poder de penetración de la ideología neoliberal. La construcción insólita de personas y estados del neoliberalismo está vaciando los principios democráticos, erosionando instituciones democráticas y destripando el imaginario democrático de modernidad europea. Se requiere, entonces, "explicar la síntesis y su mecanismo clave" (Brown, 2015: 27 - 28). Lo importante es que ello "configura a seres humanos exhaustivamente como actores de mercado, siempre, solamente y en todas partes como homo oeconomicus" (Brown, 2015: 31).

Ahora bien, ¿cómo se manifiesta la economización del sujeto por racionalización neoliberal moderna? Brown señala tres características (Brown, 2015: 31). Primero, en contraste con el liberalismo económico clásico, nosotros somos permanentemente homo oeconomicus y no podemos ser sino homo oeconomicus. Esto es una de las cosas más innovadoras que el neoliberalismo introdujo en los pensamientos políticos y sociales, a la vez que es uno de sus elementos más perturbadores. Aquellos como Adam Smith, David Ricardo y John Stuart Mill no redujeron el ser político al ser económico. 
Segundo, el homo oeconomicus neoliberal se manifiesta en la forma de recursos humanos, no de intercambios o intereses, e intenta consolidar sus propias posiciones competitivas y evaluar sus valores. $\mathrm{Y}$, tercero, hoy en día, los recursos humanos y sus zonas de actividad toman cada vez más como modelo concreto no sólo los productores y el capital empresarial, sino también el capital financiero y de inversión.

Brown se expresa de manera interesante sobre la permeabilidad de la racionalidad de gobernación neoliberal y se pregunta: ¿Cómo los seres humanos llegaron a ser comprendidos como homo oeconomicus y más específicamente como "capital humano" en todas las esferas de la vida?

El neoliberalismo ... es frecuentemente activado por medio de técnicas específicas de gobernanza de mejores prácticas y retoques legales, es decir, a través del "poder blando" aprovechando el consenso y el acuerdo más que por medio de la violencia, del comando dictatorial o incluso de plataformas políticas abiertas. El neoliberalismo gobierna como sentido común sofisticado, una realidad principal rehaciendo la institución y el ser humano en todas partes donde se instala, se sitúa y se afirma. ... Pero el neoliberalismo asemeja más a las termitas que al león ... existiendo su modo de razonamiento de manera capilar en los troncos y ramas de lugares de trabajo, escuelas, agencias públicas, el discurso social y político y sobre todo, en el sujeto (Brown, 2015: 35 - 36).

El homo oeconomicus en el neoliberalismo es significativamente distinto al del liberalismo económico clásico. El homo oeconomicus de Adam Smith, lejos de ser el ser del interés desnudo, presupone todos los elementos fundamentales, como la deliberación, la autonomía del individuo, la contención y la soberanía. El forma del homo oeconomicus para Smith, si bien responde ciertamente a los intereses, no es primitiva ni ahistórica. Los intereses se generan en las dependencias mutuas, son activados por el lenguaje y la razón, y producen las relaciones de los beneficios mutuos por medio del intercambio (Brown, 2015: 93).

A fin de cuentas, el neoliberalismo es la racionalidad por la cual el capitalismo traga al ser humano definitivamente. Su propagación "vacía el contenido de democracia liberal y transforma el significado de democracia simplemente, sojuzga los deseos democráticos y pone en riesgo los sueños democráticos" (Brown, 2015: 43 - 44).

\section{La resistencia del Sur Global}

El levantamiento del Ejército Zapatista de Liberación Nacional en 1994 fue el primer movimiento de resistencia de gran escala contra el neoliberalismo. Como es bien sabido, el inicio de la sublevación fue junto a la entrada en vigencia de TLCN (NAFTA). iBasta ya! se convirtió en el lema de diferentes resistencias latinoamericanas. Se desarrollaron así los movimientos campesinos sin tierra en Brasil y los movimientos indígenas en Ecuador y Bolivia.

En muchos países se desplegaron resistencias y protestas contra la privatización y el neoliberalismo. De este modo, el Foro Social Mundial de Porto Alegre se convirtió en un 
espacio de asamblea y discusión a escala internacional de los nuevos movimientos. Es por eso que hoy en día las comunidades indígenas se enfrentan directamente con el capital transnacional respecto a recursos naturales y están intensificando su resistencia. Las nuevas luchas de los indígenas están en los frentes del desafío al capital transnacional en torno a la compañía petrolera multinacional en Ecuador, los recursos de energía en Colombia, el gas estatal en Bolivia, el petróleo en Venezuela, las minas en Guatemala, etc.

Al mismo tiempo, se extiende a escala global la importancia y la urgencia de luchas para recuperar los bienes comunes, paralelamente a la construcción de la red social de seguridad para el pueblo. Tomemos un ejemplo: El problema del agua es un problema de la protección de la vida directamente ligado a la del pueblo. En estos momentos, aproximadamente 460 millones de personas en todo el mundo viven dependiendo de las firmas privadas de agua. En América Latina, sobre todo, se están desarrollando muchas protestas populares contra la privatización de las empresas de agua y el dominio por parte de aquellas como la Corporación Bechtel. Detrás de esta promoción de la privatización también está la demanda del Banco Mundial como condición para el alivio de la deuda. En el 2003 en Buenos Aires, los ciudadanos cerraron las calles y demandaron la vigilancia ejercida por el Congreso y la cancelación de los contratos de la privatización del agua, a partir de una protesta por el alza del precio del agua para viviendas del $88,2 \%$ y contra la provisión del agua no apta para ser bebida. En Cochabamba, Bolivia, los trabajadores, campesinos, indígenas, ambientalistas y activistas de los derechos humanos intensificaron la protesta y organizaron la Coordinadora para la Defensa del Agua y de la Vida, contra la privatización del agua. Esto hizo que la Corporación Bechtel fuera obligada a abandonar su proyecto. En octubre del 2004 en Uruguay, las elecciones presidenciales y el referéndum sobre la privatización del agua se llevaron a cabo simultáneamente, donde fue aprobada por el $64,5 \%$ la propuesta de enmienda constitucional que incluyó la prohibición de la privatización de recursos del agua como bien común.

El concepto del Sur Global incluye, bajo la globalización neoliberal, a todas las personas, grupos y clases que comparten las experiencias de explotación, alienación y marginalización. Esto es el Sur Global político o de resistencia. El Sur Global de resistencia constituye el entendimiento común de la globalización neoliberal a través del proceso como Foro Social Mundial.

Bajo la globalización neoliberal desenfrenada están surgiendo aceleradamente divisiones acentuadas y desigualdades que atraviesan las fronteras. De esta manera, la gobernanza en el Sur Global se inició con diversas objeciones contra los estados neoliberales. El neoliberalismo no es impulsado a través del retroceso del estado, sino de la reconstitución del poder estatal, y finalmente se profundizó y se expandió aún más por medio de la aparición de la nueva forma del estado: el estado neoliberal. Los principales problemas políticos y sociales que enfrentan los estados neoliberales del Sur Global, cuyo proceso de reconstitución agrava la pauperización y la exclusión, han erosionado la base de la obtención del consenso de las clases subordinadas contra la hegemonía del neoliberalismo.

\section{Hacia un nuevo proyecto de democratización}




\section{La ruptura con las ideas centradas en el Estado}

La arbitrariedad del neoliberalismo actual ha inspirado controversias en cuanto al límite, fin y ramificación del capitalismo en sí. Quisiera hacer referencia aquí a la obra reciente de Richard Falk en relación con la ramificación hacia el fin del capitalismo. Se trata de Power Shift: On the New Global Order (London: Zed Books, 2016).

Su argumento es el siguiente: La mayor parte del marco existente dominante para la acción política transnacional y global continúa estando encajada en pensamientos y hábitos de comportamientos antiguos, fuertemente ligados al horizonte temporal miope, demasiado corto para formar una reacción apropiada a los problemas graves y urgentes de la supremacía del estado soberano territorial y el futuro de la humanidad. Sin embargo, Falk argumenta, como desafío real en la era del Antropoceno, es necesario pasar del "orden mundial centrado en el estado a la comunidad política centrada en el planeta" (Falk, 2016).

El límite y la superación de las ideas centradas en el estado o territorio están también planteados desde el punto de vista del Sur Global (Bullard, 2012). El concepto del Sur Global, que se aparta del análisis centrado en el Estado-nación, constituye el marco teórico efectivo para investigar el estado actual y el paradero de la reconstrucción del mundo global por la transnacionalización del estado y por el capital transnacional como fuerza impulsora del capitalismo global. Al mismo tiempo, esto no significa abandonar el análisis dinámico de los fenómenos a niveles nacionales e interestatales. Más bien, se requiere investigar a nivel nacional las relaciones mutuas cambiantes del Estado - sociedad civil mercado en conexiones entre lo local / nacional / regional / global.

El concepto del Sur Global extiende el reconocimiento mundial del siglo XXI y reclama la examinación de estrategias de oposición por el Sur Global político y el Sur Global de resistencia, dirigidos a la constitución de la gobernanza estratificada del siglo XXI.

En cuanto a la transformación del orden mundial centrado en el estado, la forma comunitaria política centrada en el planeta está propuesta también desde el enfoque cosmopolita (Held, 1995; 2000). Anthony McGrew considera que "la globalización involucra un cambio de estructura hacia la gobernanza global estratificada" y que la globalización del estado está dando lugar a la reubicación del poder y la autoridad de los gobiernos nacionales (McGrew, 2000: 162).

\section{En consideración de la experiencia latinoamericana}

Para analizar los problemas del post-neoliberalismo y proyectar y obtener un panorama de la nueva democratización del siglo XXI, se requiere reconsiderar de manera integral las consecuencias sociales, políticas y económicas de la continua globalización neoliberal.

Del marco de la relación Estado - sociedad civil - economía, es necesario analizar la ubicación y el rol de los movimientos sociales, el elemento principal particularmente importante. Una reflexión en el caso de América Latina en la segunda mitad del siglo XX nos recuerda la explotación subordinada de la región que transformó significativamente sus estructuras sociales y económicas. Obviamente, ello alteró también la estructura de clases y de la conciencia. Entre sus experiencias cabe mencionarse el surgimiento del nuevo movimiento de trabajadores y del Partido de los Trabajadores, el rol de la Teología de la 
Liberación en democratización, los sistemas de participación ciudadana representado por Porto Alegre, los experimentos del cambio a nivel regional, particularmente la Alianza Bolivariana para los Pueblos de Nuestra América (ALBA), la gobernanza regional a nivel del pueblo y la Economía Social y Solidaria.

Lo que no debemos de olvidar es la acumulación en dicho continente de diversos experimentos, como la democracia participativa, democracia deliberativa y democracia de empoderamiento, desarrollados con el nombre de "democratización de la democracia" (Santos ed., 2005). Además, está por realizarse el proyecto de otra transnacionalización como el Foro Social Mundial (Fisher and Ponniah, eds., 2003).

En el proceso de la otra globalización, es necesario crear las condiciones para la reconstitución fundamental y rehacer la liberación social y el cambio político. Uno de estos procesos existe en América Latina. Allí, la politización de los espacios locales y la vida diaria hace que los proyectos opositores de los grupos subordinados se movilicen desde la capa más baja de la sociedad y más allá del Estado-nación. Se deben evaluar activamente estas experiencias con sus respectivas limitaciones.

Brasil jugó un gran rol para el establecimiento y el desarrollo del Foro Social Mundial. Las dificultades que tuvieron estas prácticas y proyectos debido a la resistencia y obstrucción de las clases dominantes transnacionales no les restan el valor de las experiencias.

A la vez, no está de más decir que la globalización neoliberal es la política y el movimiento a escala global, y si superarla es la tarea urgente no sólo de América Latina, sino sobre todo del Sur Global, entonces las experiencias de esta región muestran tanto práctica como teóricamente los problemas y las perspectivas en torno al post-neoliberalismo.

\section{Perspectiva de la construcción de la gobernanza estratificada}

Es indiscutible que la construcción de la gobernanza estratificada del Sur Global es una tarea extremadamente difícil. En tal caso, ¿cómo debemos proyectar la nueva democratización en América Latina? Los poderes políticos izquierdistas que comenzaron a expandirse en América Latina en el siglo XXI, si bien obtuvieron temporalmente amplios apoyos del pueblo, se han visto obligados a enfrentar el fracaso y retroceder. En consecuencia, el proyecto hacia el post-neoliberalismo inevitablemente debe ser desarrollado en vastos territorios, lo que incluye las luchas en torno a la hegemonía intelectual y cultural. Asimismo, vale la pena recalcar que esto tendría que desarrollarse dentro del vínculo estratificado de lo local / nacional / regional / global y que es necesario elaborar, desde el punto de vista de la construcción de la subjetividad del pueblo, las relaciones mutuas del estado - sociedad civil - mercado a nivel nacional.

En ese caso serían importantes los siguientes puntos de vista básicos. En primer lugar, debe darse mayor importancia a la reconstrucción democrática de la relación estado sociedad civil a partir de los puntos de vista y de referencias locales, es decir, del espacio de la vida de los ciudadanos. Si bien el levantamiento zapatista se inició en el espacio local, entrañaba el significado y el fondo histórico global.

En segundo lugar, lo necesario al proyectar la construcción de la gobernanza estratificada desde la posición de los ciudadanos es reconsiderar al Estado desde el punto de 
vista de la reestructuración del Estado y no desde la posición del retiro del Estado. El Estado no se ha retirado, sino que juega el rol promotor de participación en el capitalismo global.

En tercer lugar, cabe prestar atención, en cuanto a la reconstrucción democrática de la relación estado - sociedad civil y el proyecto de la gobernanza estratificada, a los efectos mutuos y sinérgicos entre asociaciones, movimientos sociales y la construcción del sistema democrático participativo. Las personas comunes no pueden tratar los problemas globales a partir de los problemas de sus respectivas vidas diarias.

En cuarto lugar, no se puede ignorar que las prácticas del Sur Global están promoviendo la reconsideración de los conceptos existentes. Por ejemplo, los problemas de democratización y su profundización, de las relaciones mutuas más allá de aquellas entre el sistema y movimientos, los debates sobre el antagonismo y la mediación entre el conocimiento y el poder desde el punto de vista de los ciudadanos, los problemas del nuevo rol activo de partidos políticos y la reconsideración del Estado y la sociedad civil dentro de una nueva relación Estado - sociedad civil, etc.

En quinto lugar, los puntos de discusión mencionados arriba están profundamente enredados con la búsqueda de las estrategias de reformas latinoamericanas en la era de la globalización, es decir, con la búsqueda de la nueva relación Estado - sociedad civil en el Sur Global, incluido su continente. Esto implica recuperar para el pueblo la superioridad de la política en la era de la globalización, mover la política para el pueblo y perseguir las estrategias de la reconstrucción del estado. Los siguientes argumentos por Beck se aplican al mundo que se queja del neoliberalismo:

No se puede comprar con dinero la satisfacción y la aprobación política de los ciudadanos. La producción y la reproducción de aprobación y consenso, a no ser que la economía mundial quiera sepultarse a sí misma, requieren el territorio propio como política, cultura, democracia, el Estado, que jamás se subordina a las teorías económicas. Por lo tanto, la estrategia para no renunciar al Estado es intentar re-consolidar la convicción y la experiencia contra la política vencida por el neoliberalismo. Es decir, el éxito no es posible sin políticas (Beck, 2002).

Por último, junto con los reclamos del pueblo y la búsqueda de la reconstrucción democrática de la relación estado - sociedad civil, cabe mencionar el desenvolvimiento complejo del orden global. Un ejemplo de ello se puede ver en el protagonismo global de China, que ha dejado influencias trascendentales en África y América Latina. Allí se revelan desacuerdos y antagonismos entre los intereses del estado y de los ciudadanos, fenómenos de regionalización del nacionalismo más allá de las fronteras y las nuevas facetas de la relación local / nacional / regional / global.

La más importante de estas perspectivas fundamentales es el rol de los movimientos sociales. Es porque son diversas formas de movimientos sociales tanto de los ciudadanos como de las ONGs, los que surgen del espacio de la vida ciudadana y se encargan de transformar democráticamente la relación Estado - sociedad civil y construir la gobernanza democrática de manera estratificada. 
Ensamblar desde el punto de vista del pueblo las relaciones mutuas entre el Estado, la sociedad civil y el mercado a nivel nacional, mencionado arriba, no implica menospreciar la perspectiva global. En la actualidad es indispensable también superar los pensamientos y proyectos de nivel nacional de un país. A saber, está demás decir que es imprescindible la perspectiva del Sur Global de resistencia, que se basa en el reconocimiento de la era del Sur Global.

Amartya Sen comenta sobre la relación entre la libertad y la explotación. Él considera la libertad en sí como el objetivo fundamental y como el medio más efectivo para mantener la vida económica en todas las sociedades. El desarrollo no se mantiene sacrificando la libertad y la libertad no tiene resonancia sin desarrollo. Sen señala que el desarrollo y la democratización no funcionan en espacios sociales diferentes (Sen, 1999). Es decir, el desarrollo, por un lado, no se obtiene sacrificando la democracia, por el otro. El Estado y la sociedad política no deben utilizar los movimientos sociales para la movilización política y la consolidación del estado desarrollista (de post-descolonización). A fin de continuar la democratización y los proyectos de desarrollo, el Estado debe admitir que la sociedad civil funciona en el mismo espacio social. Este espacio integra todas las relaciones sociales y conecta las acciones sociales y, por ende, es necesario la coexistencia del Estado y la sociedad civil además de su desarrollo cooperativo. Esta indicación es el marco de la construcción de la gobernanza democrática, argumentado en el presente artículo.

\section{Desde el espacio local: los comunes como las estrategias democráticas anticapitalistas}

La política del espacio, exhortada por Harvey como alternativa de la construcción de la democracia contra el capitalismo o la democracia contra el Estado, es un acercamiento importante.

Los espacios propios efectivamente constituyen sitios centrales para el encuentro de los individuos. Las características comunes y la solidaridad se establecen entre los individuos a través de esos encuentros y se pueden convertir las protestas contra la hegemonía que se oponen al orden dominante en existencias explícitas. Es desde este tipo de espacio que "se puede movilizar a los participantes para el proyecto político", que supere los intereses parciales, sin que abandone su responsabilidad en los espacios de sus actividades. A lo largo del tiempo, la fuerza sostenible de la conexión social, económica y política en los diversos espacios (desde la vecindad hasta la región y el estado) ofrece "una perspectiva práctica para las actividades políticas" (Harvey, 2009). Ahí Harvey enfoca los bienes comunes.

El cierto encierro es frecuentemente la mejor medida protectora para los bienes comunes valiosos y específicos. Harvey establece primero lo siguiente. Por ejemplo, casi no cabe ninguna duda de que se requieren los organismos del Estado para proteger los bienes comunes, sin dejar que la democracia vulgar basada en los intereses económicos a corto plazo arruine la tierra a través de plantaciones de soja y la administración del pastoreo en la cuenca del Amazonas. Por lo tanto, "no necesariamente todas las formas de encierro son rechazadas esencialmente como 'el mal'. En el mundo que se comercializa cruelmente, producir espacios no comercializados y encerrarlos es evidentemente bueno" (Harvey, 2012: 70). 
El pensamiento de proteger los bienes comunes con el encierro no siempre funcionará con facilidad, empero, es necesario que sea investigado activamente como una estrategia anticapitalista.

Harvey presenta argumentos también sobre bienes públicos urbanos y comunes. A final de cuentas, la justificación del derecho a la propiedad privada en las teorías liberales se basa en la idea de que esos derechos, siempre y cuando son socialmente integrados a través del sistema del justo intercambio de libre mercado, maximizan los intereses comunes (Harvey, 2012: 75).

Sin embargo, en la práctica el principio medular de hacerlo común es que la relación entre grupos sociales y las facetas comunes en su entorno es colectiva y no es mercantil. A saber, se excluye la lógica del intercambio y la evaluación del mercado. Éste es un punto decisivamente importante, porque es útil para distinguir entre los bienes públicos y los bienes comunes. Mientras que los bienes públicos son interpretados como egresos productivos del Estado, los comunes se crean y se usan en formas y objetivos completamente diferentes (Harvey, 2012: 73).

El neoliberalismo efectivamente apoya tanto la descentralización ejecutiva como la maximización de la autonomía local. Esto, por un lado, libera el espacio donde las fuerzas progresistas pueden promover mucho más fácilmente sus objetivos revolucionarios. Sin embargo, Cochabamba en Bolivia fue tomada en 2007 por las fuerzas reaccionarias (posteriormente expulsadas por la resistencia popular) y se estableció el dominio antirevolucionario en nombre de la autonomía. Este hecho sugiere lo problemático de los izquierdistas de presentar localismo o autonomía como estrategias abstractas (Harvey, 2012: $82-83)$.

Es por eso que existe la necesidad de establecer el bien común nuevo capaz de resistir al poder capitalista.

El desmantelamiento de los marcos y controles regulatorios que buscaron, independientemente del que fuere, frenar la inclinación por prácticas predatorias de acumulación ha liberado la lógica de Tras mí, el diluvio de acumulación y especulación financiera desenfrenadas que ahora se han convertido en una verdadera presa de destrucción creativa, incluido aquello forjado a través de la urbanización capitalista. Este daño sólo puede ser contenido y revertido por la socialización de un nuevo común de la riqueza abierta para todos. ... El reconocimiento político que los comunes pueden ser producidos, protegidos y usados para beneficio social se vuelve un marco para resistir al poder capitalista y repensar las políticas de una transición anti-capitalista (Harvey, 2012: 86 - 87).

Para ello, se requiere un ataque político de doble filo. Es decir, el Estado se ve obligado a proveer cada vez más en forma de bienes públicos para objetivos públicos, junto con la auto-organización de toda la población que posea, utilice y complemente estos bienes de maneras que se extiendan y mejoren las calidades de los comunes no mercantilizados reproductivos y ambientales (Harvey, 2012: 87 - 88). 


\section{Sociedad civil - Estado (espacio político) - mercado (espacio económico)}

Los movimientos sociales del siglo XXI comenzaron a enlazar los aspectos de los objetivos del socialismo y el nuevo movimiento enfocado a la organización participativa y a buscar un enfoque que transforme la relación de poder entre el Estado, la economía y la sociedad civil. Además, la amplia participación de la sociedad civil está creando alternativas en espacios locales. Enfocar la resistencia a gran escala en busca de la concesión del Estado como antes ya no parece producir resultados deseables. Por ende, las prácticas creativas de movimientos sociales en el interior de la sociedad civil es uno de los territorios más realistas y efectivos para superar el dominio de mercado y la indiferencia del Estado. Esto implica definitivamente buscar la concesión del estado a través de las nuevas prácticas alternas a nivel local. En este proceso, hubo un nuevo desafío de democracia participativa y su consolidación del rol ciudadano en la toma de decisiones que influyen sus propias vidas. Esta transformación de la objeción al actor estatal, en la atribución de importancia a la alternativa mediante los sistemas de la sociedad civil, es uno de los desarrollos más significativos de los movimientos recientes.

Los presupuestos participativos de Porto Alegre y los planeamientos descentralizados de Kerala fueron casos notables de los movimientos creativos de los sistemas sustitutivos. A continuación, voy a tratar la experiencia de Movimientos de los Trabajadores Rurales Sin Tierra de Brasil y la Economía Social y Solidaria.

\section{Movimientos de los Trabajadores Rurales Sin Tierra (MST)}

Los casos del MST han mostrado la importancia de la construcción organizativa de base con la capacidad colectiva de desafiar la relación del poder político y económico dominante concerniente a la tierra (Voss and Williams, 2009: 18 - 19). El MST se organizó para la lucha colectiva en 1984 y demandaba el uso y la posesión de la tierra no productiva por los mismos trabajadores sin tierra. Su práctica está basada en la pedagogía de Paulo Freire, es decir, en el aprendizaje participativo. EI MST ha venido enfocando consistentemente la organización de base. No aparece allí un solo dirigente individual. Al contrario, se reproduce continuamente el liderazgo colectivo. Esto, a través de la obtención amplia de apoyo de la sociedad civil, incluida la clase media, enlaza la lucha de la tierra local con el proceso transformativo local de la relación de poder y con la lucha a gran escala para la construcción de un nuevo mundo. A la vez, no ignora el rol activo que juega el Estado.

Para el momento del cambio de siglo, 350 mil familias (aproximadamente 4 millones de personas) obtuvieron la utilidad de las tierras distribuidas por la ocupación liderada por el MST. En los últimos años, el MST está extendiendo las redes internacionales, construyendo así relaciones importantes con otras organizaciones. Por ejemplo, el MST ha jugado el papel principal en la formación del Foro Social Mundial y se ha desarrollado hasta tal punto que cuenta con fuertes alianzas nacionales e internacionales.

\section{La Economía Social y Solidaria (ESS)}

La Economía Social y Solidaria busca principios y elementos estructurales comunes. Sus objetivos son, primero, servir no al simple beneficio financiero, sino a la comunidad y sus miembros. Segundo, ser las empresas de la Economía Social y Solidaria (ESS) indepen- 
dientes del Estado. Tercero, sus reglas y normas de conducta se forman por toma de decisiones democráticas, lo cual implica la necesaria participación de usuarios y trabajadores. Cuarto, priorizar el pueblo y trabajadores antes que el capital en la distribución de ingresos y excedentes. Además, sus actividades se desarrollan sobre la base de participación, empoderamiento y la responsabilidad colectiva e individual (Neamtan, 2002: 2 - 3).

La ESS, en vez de perpetuar la economía de mercado, debe desplegar la economía acompañada por mercado. Es decir, pretende la integración tanto de elementos económicos como sociales.

Por ende, la lucha de la ESS debe emplear los valores de solidaridad e igualdad, y apoyarse extensamente en movimientos sociales. Para ello es necesario que sus actividades reconozcan con claridad las relaciones mutuamente complementarias y cooperativas. En este sentido, la presencia de la ESS en el Foro Social Mundial muestra el avance importante hacia este objetivo (Neamtan, 2002: 14).

La ESS fue uno de los programas básicos de resistencia social y política de los gobiernos y sociedades latinoamericanos a las políticas neoliberales. Fue discutido como construcción del marco político regional que sustituye al desarrollo basado en el mercado.

Los estudios sobre la economía solidaria tienen como objetivo la satisfacción del bien común en base a cierta territorialización. Concretamente se refieren, por ejemplo, a la relación entre el Estado y el mercado, la subjetividad de organizaciones de la sociedad civil, los procesos democráticos no sólo en la economía, sino también en espacios locales y la solidaridad y movimientos internacionales. Sin embargo, si bien la economía solidaria como una forma de gobernanza local puede afirmar suficientemente su sentido realista, sus limitaciones se le suponen como alternativa de globalización neoliberal. Ahora es indispensable que sea ampliamente debatida la posibilidad de reflotar la solidaridad y la integración regionales de América Latina.

Lo importante es construir diversas oportunidades subjetivas de manera estratificada y solidaria, poniendo las miras en el proyecto hegemónico de resistencia a la globalización neoliberal. Para ello tiene que ser construida una alianza que atraviese territorialmente las personas que actúan bajo diferentes y propias condiciones de historia, cultura, localidad, política y economía, y se requiere un mutuo acuerdo establecido en cuanto a objetivos comunes (Harvey, 2010). En tal caso, es imprescindible la profundización de la democracia y la construcción social democrática en nivel nacional, a saber, políticas para el pueblo. Para que la economía solidaria se convierta en sistema alternativo para el mercado, es también indispensable hacer de la política lo propio del pueblo soberano.

\section{Movimientos independientes de las comunidades}

Partiendo del espacio local, tanto el MST como la ESS se han extendido más allá de sus fronteras. Voy a presentar a continuación las experiencias recientes de movimientos independientes de las comunidades en busca de métodos sustitutivos efectivos contra el neoliberalismo en Sudamérica (Cepeda, 2021).

Buen vivir, la palabra de los indígenas de Ecuador, los movimientos de resistencia zapatistas, la Vía Campesina y su soberanía alimentaria, etc., son todas realidades obser- 
vadas en el Sur Global. La Campaña de Soberanía Alimentaria Sudafricana se dio al grito de No Puedo Respirar. Los zapatistas gritaron iBasta ya!, y los campesinos de México, iNo aguanto más! Son los gritos generados por la globalización neoliberal desenfrenada y ahora desesperadamente en su contra.

En estas experiencias están incluidos los movimientos de resistencia basados en el pluralismo y formas sustitutivas de la organización social, producción y consumo. El desafío verdadero a la racionalidad neoliberal (Wendy Brown) en Argentina y Bolivia demuestra la amplitud del espacio de resistencia a la globalización y la necesidad de explorar diversos contextos sociales.

Uno de ellos es la resistencia andina en los campos de coca. La población de la región del Chapare en Bolivia no sólo lucha contra el desempleo y libre mercado relacionado a la explotación de los recursos naturales, sino también contra secuelas del Estado, incapaz de satisfacer las necesidades básicas y la guerra contra las drogas.

La coca tiene una raíz histórica y cultural profunda, y es ampliamente consumida. Las políticas neoliberales de los años 80 y 90 quitaron las industrias y empleos de esta región, lo cual hizo de la expansión del cultivo de coca la única forma de ganarse la vida para muchas personas. Los campesinos del cultivo de coca o familias cocaleras de la región del Chapare desarrollaron algunas estrategias para proteger su vida y sus derechos. La más conocida ha sido manifestaciones en gran escala y los actos como bloqueo de rutas principales del transporte. Sin embargo, algunas de estas estrategias llevaron consigo enfrentamientos directos y violentos con la policía y el ejército.

La región del Chapare derriba el Estado y lo apoya, independizando el suministro de servicios sociales y mercancías. Está organizada para mancomunar los recursos de su propia comunidad, los organismos internacionales, del gobierno central y para que los ciudadanos se encarguen de su educación, justicia, servicios médicos y viviendas. De esta manera, las personas participan en la democracia boliviana. Chapare envía periódicamente los candidatos que representan sus intereses en la participación de las elecciones regionales y nacionales.

Este tipo de resistencias cotidianas han tenido éxitos considerables. Desde 1994, los campesinos del Chapare han tenido varios triunfos regionales y estatales tanto en el ejecutivo como en el legislativo. El presidente Evo Morales de Bolivia es originario de una familia cocalera y ha dirigido la unión de productores de coca del Chapare.

Con el incremento de su representación política, los campesinos enmendaron efectivamente la ley de la coca. Actualmente está permitido el cultivo de coca de 1 cato $(1,6$ $\mathrm{km}^{2}$ ) por familia. A pesar de que esta enmienda exasperó a los Estados Unidos, Bolivia expulsó a la Administración para el Control de Drogas, que criticaba la legalización de la coca.

Estos actos están socavando directamente el paradigma del neoliberalismo. En su proceso, los campesinos del Chapare han consolidado la solidaridad con las comunidades de aquellas personas en marginalización y allí se han generado las diferencias de opiniones entorno principalmente a los problemas del medioambiente. Sin embargo, la región muestra cómo el ser humano es capaz de vivir en armonía en una sociedad donde se consideran 
las diversas realidades y las necesidades de los otros.

Ahora bien, quisiera mencionar sobre los Movimientos Multisectoriales de Argentina. Los Movimientos Multisectoriales urbanos de la Argentina contemporánea están constituidos por un grupo diverso que incluye desempleados, trabajadores sindicalizados, estudiantes, inmigrantes, amas de casa, artistas y académicos. Estos movimientos tienen su origen en las protestas de piqueteros tras la crisis económica argentina de 2001. En el transcurso de dicha crisis, la pobreza había incrementado un 50\%. Los piqueteros protestaron bloqueando las calles en el centro de la ciudad de Buenos Aires y demandando empleos y salarios.

A medida que fue mejorando el empleo bajo los gobiernos izquierdistas de Néstor Kirchner (2003 - 2007) y Cristina Fernández (2007 - 2015), los piqueteros comenzaron a diversificar sus reclamos, los que incluyeron otras necesidades como la dignidad, la solidaridad, el acceso a servicios sociales y la participación política. La ideología del movimiento estaba basada en el supuesto de que ni el Estado ni el mercado pueden satisfacer estas demandas. Hoy están incluidos en las actividades principales de este movimiento facilitar el acceso a los servicios de salud, al espacio público y la educación para comunidades excluidas de las grandes ciudades como Buenos Aires, La Plata y Rosario.

Así como los productores de la coca en Bolivia, los Movimientos Multisectoriales de Argentina están intentando expandir los mensajes de resistencia a la sociedad cada vez más extensa. Este proceso democrático progresista les posibilita a ambos desarrollar las relaciones de solidaridad consolidada con comunidades constituidas. Enfocando el empoderamiento y acciones, realza la conciencia de los ciudadanos y promueve su concientización respecto a los problemas públicos y exhorta a adoptar posiciones.

A raíz del mejoramiento del empleo en el gobierno de Néstor Kirchner, los opositores demandan ahora la dignidad y la inclusión. Estos movimientos multisectoriales reabrieron el diálogo nacional en Argentina sobre la democracia, el estilo de producción y el consumismo, que son los soportes teóricos del neoliberalismo.

\section{El significado contemporáneo de gobernanza regional}

El globalismo implica el desarrollo del mercado mundial y su penetración y dominio cada vez mayor en la economía del pueblo, cuyo proceso hace desvanecer ciertamente la nacionalidad determinada. Esto significa la superioridad del mercado mundial sobre estructuras productivas locales y la difusión acelerada del consumismo del modelo europeo occidental. Por otro lado, los procesos de globalización y regionalización son unidos al interior del proceso en gran escala de la transformación estructural igualmente global. He ahí una nueva posibilidad de regionalismo como forma de lograr cambios donde puede aparecer la voluntad política que frene o invierta el proceso de globalización con el fin de proteger cierto grado del dominio territorial y la diversidad cultural. En otras palabras, nace la expectativa hacia el rol del "regionalismo como fuerza opositora contra la reestructuración neoliberal" (Hirst and Thompson, 1996). Tal es así que para la realización de la gobernanza global nos vemos obligados a prestar atención al rol realista y latente de la gobernanza regional. Es por eso que hay muchos teóricos que buscan la posibilidad del regionalismo autónomo y resistente, con la esperanza de que los organismos regionales se 
conviertan en la barrera contra la globalización y la hegemonía de los Estados Unidos.

Según Richard Falk, a partir de un punto de vista idealista sobre la gobernanza regional, el regionalismo se puede utilizar idealmente como medio para "moderar el anarquismo anormal". Es decir, se considera que, "desde el punto de vista del orden mundial, el rol del regionalismo sirve para generar el nuevo equilibrio político que balancea la protección de los débiles y los beneficios de la humanidad (incluidas las generaciones futuras) ante el dinamismo integral y tecnológico ligado al globalismo" (Falk, 1995).

\section{Emergencia de resistencias locales}

Los actores como el Estado, el mercado, la sociedad civil y los actores exteriores no actúan autónomamente. Esto no es el problema del regionalismo liderado por el Estado versus el regionalismo liderado por el no-Estado. Al contrario, dichos actores se unen con frecuencia en el conjunto de actores compuestos, las redes y la gobernanza regional.

El mercado, el Estado y la sociedad civil están en las relaciones de efectos mutuos y están en una posición crucial, siendo la composición subregional su forma de reaccionar al desafío de la globalización. El sub-regionalismo es un fenómeno dependiente de las condiciones históricas en una encrucijada de la globalización. Entre las diversas formas de regular la globalización, puede emerger la resistencia como la única opción.

Con el fin de politizar el proceso de la globalización en el sentido del control de la sociedad democrática y ciudadana, se debe suponer la diversidad de influencias políticas y opositoras. Esto implica descubrir "la base sólida para pronosticar el diseño de la estructura política del futuro". Esta base podría tener la forma de resistencia local y regional. "La resistencia es localizada, regionalizada y globalizada al mismo tiempo que la globalización económica corta transversalmente las fronteras geopolíticas" (Mittelman, 2000: 177). Esta indicación de Mittelman está en el fondo de los movimientos del Foro Social Mundial mencionado previamente.

\section{Gobernanza regional como contra-estrategia}

El regionalismo fue principalmente la medida defensiva en los años 80 contra la marginalización económica de muchos países del sur, la reorganización política del período de cambios violentos políticos y económicos por el fin de la Guerra Fría, el miedo económico y la reacción globalizadas; pero también tuvo los movimientos hacia nuevas etapas.

Hoy, bajo la globalización neoliberal se evidencia la cadena compleja, estratificada y negativa desde el nivel global hasta local. Por ende, aumentan las demandas de la necesidad de domesticar la globalización y la construcción estratificadas de la gobernanza democrática. Esto está relacionado tanto con los puntos de vista locales como con la nueva posibilidad del regionalismo. Es decir, merece la atención el punto de vista del control de la globalización neoliberal desde la posición ciudadana, el punto de vista de encajar la globalización en la sociedad civil y, además, el rol y la posibilidad del regionalismo como la fuerza opositora contra la reestructuración neoliberal. Desde luego y paralelamente, la recomposición democrática del estado tiene la importancia determinante.

James Mittelman propone importantes interrogaciones fundamentales respecto a la 
posibilidad del regionalismo contemporáneo: ¿El plan de regionalización puede ser desarrollado para frenar la tendencia antisocial del capital transnacional? ¿El regionalismo tiene el potencial para proveer el espacio que crea las nuevas influencias para el futuro de la post-globalización? ¿El regionalismo no es más que un punto transcurrido de la globalización neoliberal o está en camino del orden mundial pluralista donde existen varias organizaciones económicas y sociales que compiten en busca de apoyo del pueblo (Mittelman, 2000)? Es así como Mittelman plantea los problemas.

El regionalismo tiene la posibilidad de superar el nacionalismo intolerante y empujar la conciencia de la sociedad civil hacia la dirección transnacional y finalmente universal. Por esta razón, la verdadera cuestión es qué tipo de influencias se debe desplegar bajo qué condiciones y qué composiciones.

\section{La emergencia del regionalismo liderado por Sudamérica}

En el período del cambio del siglo, estaba presente la expectativa de la realización del proyecto Área de Libre Comercio de las Américas (ALCA), bajo la hegemonía de los Estados Unidos. El proyecto tenía la intención de formar la red expansiva de convenios comerciales neoliberales, involucrando al Norte Global y el Sur Global. Sin embargo, el proyecto ALCA en su totalidad se rompió en la Cumbre de las Américas (Mar del Plata) de 2005.

En Sudamérica se había sido instalado el MERCOSUR (Mercado Común del Sur) en 1991. Al principio, el MERCOSUR era considerado como un proyecto neoliberal. El Tratado de Asunción, que instaló el MERCOSUR, fue esencialmente un convenio comercial sin objetivos sociales de ningún tipo. Fue básicamente una negociación entre los gobiernos dirigidos por los neoliberales sin la participación de los actores sociales. Nacen, sin embargo, dos iniciativas de integración regional que objetaron la integración dirigida por los Estados Unidos. Éstas fueron UNASUR (Unión de Naciones Suramericanas) dirigida por Brasil y ALBA (Alianza Bolivariana para los Pueblos de Nuestra América) dirigida por Venezuela.

\section{UNASUR (Unión de Naciones Suramericanas) y ALBA (Alianza Bolivariana para los Pueblos de Nuestra América)}

El origen de UNASUR fue la Comunidad Sudamericana de Naciones (CSN) establecida en el Encuentro de Presidentes de América del Sur (Cusco) en el 2004, cuyo nombre fue cambiado a Unión de Naciones Suramericanas en la primera Cumbre Energética Sudamericana del 2007. Si bien UNASUR desafía la hegemonía de los Estados Unidos en esta región, está completamente incorporada en la teoría de la acumulación del capital y del dominio empresarial. UNASUR estaba basada en la política desde arriba, en cuyo fondo está la estructura del poder de las clases de América Latina. Es por eso que fue un negocio peligroso dirigido por Brasil y recibió advertencias sobre la subordinación futura a la hegemonía regional de Brasil.

Por otra parte, también emergió la integración regional desde abajo. En diciembre del 2006, paralelamente a la segunda Cumbre de la CSN, más de 4.000 representantes se reunieron en la Segunda Cumbre Social por la Integración de los Pueblos. En esta cumbre participaron los sindicatos de los trabajadores, organizaciones campesinas y los activistas 
de otras organizaciones de base. Fue evidentemente un rechazo al neoliberalismo y al ALCA. Si bien ellos reconocieron la necesidad de desarrollo infraestructural de la región, reclamaron que los proyectos demasiado inclinados al capital internacional y "las propuestas integrales de la infraestructura lejos de las demandas de los pueblos debían ser rechazados" (Kellogg, 2007: 198 - 199).

Contrariamente, el ALBA está fuertemente ligado a los movimientos populares y estaba en el centro de la tendencia izquierdista de muchas políticas de la región. Según Hugo Chávez, el ALBA es "el modelo integral flexible de América Latina en cuya primera línea están los intereses sociales. Las cooperaciones entre los dos países se basan no sólo en los principios de solidaridad, ... sino también en los intercambios de bienes y servicios más beneficiosos para las necesidades económicas y sociales entre ambos países". Este comercio, de hecho, no sólo se limita al comercio, sino que va más allá, enfocándose en problemas sociales importantes, como las actividades de alfabetización. Como parte del acuerdo del comercio, Cuba ofreció 2.000 becas universitarias anuales a los jóvenes de Venezuela. Además, el país permitió a la Universidad Simón Bolívar utilizar libremente a más de 15.000 especialistas de medicina. Ambos países acordaron también tener cooperación en la salud para un tercer país.

El ALBA llegó al acuerdo en "la consideración de la asimetría política, social, económica, legal de ambos países y en la posibilidad del comercio complementario" de ambos gobiernos a través del intercambio de bienes que esquivan el mercado financiero (Kellogg, 2007: $200-201)$.

\section{La gobernanza regional por los pueblos}

Aún en la era de la globalización, el Estado no puede ser ignorado, al ser el actor que juega continuamente el rol crucial en el proceso de la regionalización. Sin embargo, es indispensable prestar atención a la variedad de actores no estatales. Los actores detrás de los proyectos regionales no sólo son el Estado, sino también los sistemas, organizaciones y movimientos de diversas índoles. El regionalismo de hoy es más extrovertido que introvertido.

La conceptualización del regionalismo contemporáneo se puede considerar más ampliamente que el regionalismo antiguo en los siguientes puntos relacionados. El primero concierne al agente. Los actores de la regionalización se encuentran en el triángulo del Estado, sociedad civil y mercado. Son diversos y van desde las élites hasta los niveles de base, desde los individuos hasta las comunidades y desde los elementos oficiales hasta los no oficiales. Esta categoría incluye innumerables agentes, como ONG, diásporas, sindicatos laborales, medios de comunicación, empresas nacionales y transnacionales, grupos de presión, poderes políticos, redes, grupos de investigadores, organizaciones internacionales, etc.

El segundo tiene que ver con el vector y la motivación. La integración de los actores no es solamente estimulada por la maximización de la seguridad, sino también por otros aspectos relacionados a la sociedad, el medioambiente, la política o la economía, etc. Y el tercero, con la direccionalidad. Las regiones no son realidades existentes que obedecen a la estructura histórica permanente. Son creadas espontáneamente por los actos del ser humano y las prácticas sociales como consecuencia de la permanente redefinición de los procesos e intereses, y son formadas a partir del proceso mutuo continuo entre socieda- 
des y personas.

A fin de cuentas, los actores, como el Estado, mercado, sociedad civil y actores exteriores, no actúan autónomamente. Ellos se unen en el conjunto de actores compuestos, las redes y en la gobernanza regional. De esta manera, la ausencia de la simple definición con respecto a los organismos y sistemas regionales interestatales oficiales es una de las características del regionalismo contemporáneo (Söderbaum, 2003: 1-2).

\section{La Construcción de la gobernanza estratificada del siglo XXI: hacia un proyecto de la globalización alternativa}

\section{La reconstrucción del poder territorial y el sistema democrático}

Entre diversos puntos decisivos de la penetración y la profundización del neoliberalismo, merece la atención el hecho de que éste ha venido penetrando a través del discurso neoliberal hasta en el último rincón de la sociedad con el propósito de procurarse y diseminar el desarrollo de la informatización y el consentimiento del pueblo basado en ello. La doctrina y las políticas del neoliberalismo aún ocupan un lugar profundamente dominante en todos los territorios y espacios, incluso en el estilo de pensamiento del pueblo. Está de más decir que esto ocurre igualmente en las empresas, organismos internacionales, sectores de la educación y de los medios de comunicación. Las sociedades y la sociedad civil en las cuales se basa el sistema democrático se han visto contaminados y socavados por dentro. Como fue mencionado anteriormente, el discurso neoliberal se volvió predominante y está infiltrado profundamente en las formas de pensar como sentido común (Harvey, 2005: 11). Así lo reconoce David Harvey.

Respecto al discurso neoliberal, quisiera centrarme en los estudios de Frédéric Lordon, Wendy Brown, y Christian Laval (Lordon, 2010; Brown, 2015; Laval, 2007). Estos autores han estudiado cómo se manifiestan la infiltración y el desenvolvimiento del neoliberalismo no sólo en las oportunidades violentas que aparecen en las estructuras superficiales, sino también cómo sus discursos propios penetran en los troncos y las ramas del sujeto, y en sus venas capilares en formas peculiares, que podrían llamarse el poder blando, a través de las estructuras profundas y del sentido común de la vida diaria social.

En el presente artículo fueron tratados también algunos puntos sobre el desarrollo de la informatización, la infiltración y la profundización del neoliberalismo basado en ello. Estos han sido reflejados en las tendencias reales de la consolidación del control de las fronteras y las sociedades controladas. Por otro lado, he discutido también sobre la situación actual de la globalización en el Sur Global, en la cual aparece el mercado de las tierras y avanzan el ahuecamiento y la reubicación del estado. Los anteriores se conciernen a la lógica capitalista del poder y los posteriores a la lógica territorial del poder, referidos por Harvey.

Harvey indaga la teoría territorial y la teoría capitalista del poder y enfatiza la necesidad de buscar la reforma y la reconstrucción fundamentales del poder territorial. La lógica territorial del poder se refiere a las estrategias políticas, diplomáticas, económicas y militares, desarrolladas por las estructuras del estado en base a los intereses propios. 
Por otra parte, la lógica capitalista del poder enfoca la manera en que el poder monetario fluye más allá de las fronteras, atravesando espacios en busca de la acumulación sin fin (Harvey, 2010: 204 - 205).

Mientras que la mayor parte del pensamiento anti-capitalista contemporáneo es escéptico o completamente hostil a cualquier giro hacia el Estado como una forma adecuada de contra-poder a aquel del capital, algunas clases de la organización territorial (como la dispuesta por el movimiento revolucionario zapatista en Chiapas, México) son inevitables en el diseño de un nuevo orden social. La pregunta, por lo tanto, no es si el Estado es una forma válida de organización social en los asuntos humanos, sino qué tipo de organización territorial de poder podría ser apropiada en la transición a alguna otra forma de producción (...) por lo tanto, cualquier transición lejos de la acumulación del capital como la forma dominante de organizar la reproducción de la vida social tiene que anticiparse a una transformación radical y la reconstrucción del poder territorial. Los aparatos institucionales y administrativos nuevos, operativos dentro de algún territorio, necesitarán ser diseñados (Harvey, 2010: 207 - 208).

Esto es uno de los proyectos más importantes para la reconstrucción del Estado neoliberal y la sociedad actual en la dirección democrática, y será el punto de partida de las ideas fundamentales.

\section{La hegemonía neoliberal y los límites de su legitimidad}

En el 2018 se sustanciaron cambios políticos decisivos para este continente. En octubre de ese año, el poder político del Partido de los Trabajadores, que había venido gobernando el Brasil por cerca de treinta años, fue tomado por Jair Bolsonaro, un ex militar de la extrema derecha. Por otro lado, Andrés Manuel López Obrador ganó las elecciones presidenciales en México en julio. Los cambios políticos en estos dos países grandes reflejan la vida de sus pueblos de respectivos países en situaciones complejas, causadas por las influencias transnacionales lideradas por el neoliberalismo y los Estados Unidos. En el caso de México, hay que considerar el significado profundo del lema, "¡Basta ya!", el grito del pueblo extenso. Esto representa, entre otras cosas, la caída y la depreciación económica, la destrucción de la vida por el capital global, las inmigraciones casi forzadas, la propagación de la violencia y la corrupción.

El gobierno de Bolsonaro jugará un rol promotor en la profundización del neoliberalismo en las regiones americanas, fomentando el conservadurismo. López Obrador, por otro lado, tanteará la posibilidad de una dirección diferente y contraria al gobierno de Bolsonaro. El surgimiento del gobierno de López Obrador en particular, si bien existen los elementos inciertos, merece la atención histórica en el sentido del trato con el neoliberalismo y de proyectar el destino de América Latina.

Lo importante es si la labor del nuevo gobierno de México puede llegar a obtener el liderazgo regional e integral o convertirse en el núcleo más allá del nivel nacional. En otras palabras, es indispensable que tengan las estrategias para construir la gobernanza local, nacional, regional, democrática y estratificada. 
Hoy en día, se exigen nuevas teorías. Es una tarea inevitable la solidaridad entre las diversas hegemonías opositoras. Hay amplia bibliografía sobre los movimientos sociales y también existen controversias teóricas. Sin embargo, muchas de ellas son predominantemente elaboradas por los académicos de Europa occidental, las cuales hacen referencia respecto a la mayor parte de la historia y las prácticas de los movimientos sociales. Como señala Gaventa, con algunas excepciones, "no se toma en cuenta la rica historia de los movimientos sociales del Sur Global, ni están escritas a través de los lentes académicos profundamente arraigados en los ambientes del Sur Global" (2010: xii).

La historia del Sur Global y especialmente de América Latina, a lo largo de los cambios sociales y estructurales dinámicos, han experimentado los movimientos creativos, democráticos y complejos. Además, en diferentes sentidos "las dinámicas más profundas y conceptualmente invisibles están atravesando los países y lugares muy diversos. Veo en función una sistematicidad global por más localizados que estén representados" (Sassen, 2014: 209)

Bajo la globalización capitalista, el capital continúa buscando ensanchar las nuevas salidas e intenta agresivamente continuar comercializando los espacios de reproducción social, como la familia, la comunidad y el espacio público. No obstante ello, las bases para expandir, profundizar y justificar el sistema están llegando a sus límites. Ya no es sólo un ideal buscar un desarrollo de las fuerzas promotoras de la hegemonía opositora, que sustituye al capitalismo global a través de la solidaridad de las influencias sociales desde abajo, tales como las luchas laborales entorno a la producción, las luchas comunitarias entorno a la reproducción y las luchas políticas en la sociedad política.

Lo importante de esta clase de solidaridad es el sindicalismo al estilo de los movimientos sociales en los aspectos de la producción, por un lado, y los trabajadores organizados y la comunidad de las clases populares en los aspectos de la reproducción social, por el otro (Robinson, 2014: 235). La clase trabajadora se refiere a los trabajadores marginalizados, lo que incluye a las mujeres, a los trabajadores inmigrantes, a los trabajadores del hogar, a los trabajadores temporales, especiales y aquellos a medio tiempo. "El empoderamiento de la clase trabajadora global involucra a una completamente nueva concepción de la organización laboral y sindicatos; esto involucra a la organización de los trabajadores del sector informal, los desempleados, los trabajadores inmigrantes, los trabajadores de medio tiempo y aquellos contratados, etc." (Robinson, 2014: 235). Por ende, desafiar el capitalismo global necesita una nueva forma creativa de organización.

Es primordial construir estratificada y solidariamente las diferentes oportunidades subjetivas con miras al proyecto por la hegemonía opositora contra la globalización neoliberal. Para ello, deben construirse alianzas que atraviesen los territorios, entre las personas que trabajan en condiciones diferentes y propias de la historia, cultura, localidad, política y economía; son necesario también acuerdos establecidos sobre los objetivos comunes.

\section{Las estrategias de resistencia a la globalización neoliberal del siglo XXI}

Las estrategias de resistencia a la globalización neoliberal del siglo XXI requieren estudios sobre las relaciones cambiantes entre el Estado, la sociedad civil y el mercado a 
nivel nacional, dentro de la relación consolidada de lo local / nacional / regional / global. En otras palabras, es necesario buscar diversos proyectos que incrusten el Estado en la sociedad civil, construir el regionalismo basado en el pueblo y buscar a largo plazo en el nivel global el mecanismo de la toma de decisiones por consenso fundado en la igualdad y la diversidad. Podrían unirse a las estrategias de resistencia del siglo XXI los movimientos como el Foro Social Mundial (Ver la Carta de Principios de FSM; Fisher and Ponniah, eds., 2003) que reconoce la complejidad de los procesos históricos, económicos, culturales y políticos (desiguales y consolidados) de la represión y la marginalización y que a la vez desarrolla los métodos operativos innovadores de resistencia; y también aquellos esfuerzos teóricos que proponen el sistema democrático cosmopolita (Held, 2002).

Merece ser mencionado aquí el punto de vista de la construcción de la gobernanza estratificada. La promoción de la reforma neoliberal es un proceso acompañado por elementos nacionales y globales. Como fue enfatizado por muchos teóricos, el orden mundial neoliberal predominante no se puede cambiar sólo en el nivel local y nacional. Es decir, la lucha efectiva para la transformación social global necesita la unión de los movimientos diversos y estratificados desde la resistencia local hasta la coordinación transnacional. En este sentido, cabe decir que lo que indica Robert Cox es persuasivo.

Dicho de otro modo, la salida del callejón creado por la desregulación económica y la despolitización se encuentra en la re-regulación y la re-politización que correspondan a los cambios estructurales globales. Esto no puede ocurrir de golpe en un solo país. Cox señala que la separación y el aislamiento basados en un solo país sería la destrucción de sí mismo (Cox, 1994: 110). Por consiguiente, es indiscutible que lo ideal es que se produzca a través de las resistencias y los movimientos locales con base en la sociedad civil, la solidaridad y la coordinación de la gobernanza estratificada, que abarca desde lo local hasta lo global.

\section{Conclusión: aprendizaje desde el Sur Global}

La globalización neoliberal ha penetrado en las regiones de todo el mundo no sólo transformando el Estado, sino también dando un golpe directo a la vida de las personas. Sus influencias se manifestaron en la crisis a escala planetaria y en toda clase de diferencias y divisiones. En resumen, es la destrucción de la seguridad del ser humano en sus territorios económicos y sociales. Hoy están cobrando fuerzas los movimientos ciudadanos de objeción, que se dirigen desde el Sur Global al post-neoliberalismo. Por otro lado, la democracia es cada vez más de nombre, los espacios públicos se reducen y el mundo se inclina hacia el autoritarismo y totalitarismo.

La tendencia global obviamente ha involucrado a los países de Asia también y lo mismo sucede allí en cuanto a la introducción de las políticas neoliberales. En Japón se intensifica la tendencia nacionalista o el nacionalismo intolerante. Los espacios públicos para sus ciudadanos se están estrechando cada vez más bajo los gobiernos conservadores, que han durado mucho tiempo. Además de ello, la Constitución de Japón está quedando de nombre. En el fondo de estas situaciones están la particularidad del neoliberalismo japonés y sus consecuencias.

Quisiera, por último, resumir algunos puntos importantes. Primero, el crecimiento 
económico de Japón como el sistema del estado desarrollista dependía del dominio empresarial y los movimientos sindicales según principios empresariales, el sistema subcontratista y del sistema político fiscal con la priorización empresarial por el partido gubernamental a largo plazo = el Partido Democrático Liberal.

Segundo, con excepción de las municipalidades, existe una debilidad de los movimientos, pensamientos y proyectos en la sociedad contra el neoliberalismo. Los movimientos sindicales están incorporados en las empresas y no pudieron solidarizarse con los movimientos ciudadanos y oponerse a las políticas neoliberales.

Tercero, las políticas patrocinadoras por el Partido Democrático Liberal, la solidaridad entre los órganos burocráticos complementarios, las fuerzas conservadoras y la ausencia de la alternación de los poderes políticos, entre otras cosas, garantizaron efectivamente la acumulación del capital por el neoliberalismo.

Cuarto, hay que mencionar también sobre el rol y la posición del Japón en su relación con Asia, especialmente con China, Corea del Sur y Corea del Norte. Ante estos países, el gobierno japonés ha continuado formando consenso con el pueblo a partir de la instigación de la xenofobia y el nacionalismo intolerante.

Actualmente la situación política de Asia es extremadamente fluida. La sociedad civil en el proceso de formación en Hong Kong, Taiwán, Tailandia y Myanmar en los últimos años está, en la presente etapa, frente a frente con los sistemas autoritarios, incluida China; por lo cual, la tarea es construir una solidaridad de la sociedad civil que supere las limitaciones de la soberanía nacional, es decir, construir la sociedad civil en el nivel regional. Es de mucha envergadura cómo el Japón y los ciudadanos japoneses pueden vincularse con estas tareas.

Al mismo tiempo, hoy en día es evidente el límite de la hegemonía neoliberal y su legitimidad. La crisis del siglo XXI está agravándose cada vez más por la profundización de la globalización neoliberal. El conjunto de problemas a los que se enfrenta la humanidad es la crisis que amenaza la seguridad del ser humano, que incluye el medio ambiente planetario, la crisis del ecosistema y las epidemias devastadoras, como la del coronavirus.

La gran mayoría de la humanidad no se beneficia del neoliberalismo. El proyecto para el post-neoliberalismo debe ser desarrollado en los vastos territorios a partir de la integración de las luchas en torno a la hegemonía intelectual y cultural. Ello implica, en vista de que el orden centrado en el Estado está llegando a sus límites, la búsqueda de la construcción de la gobernanza estratificada a través de los espacios locales y las luchas por los bienes comunes. Esto exigirá la construcción de la democracia y el espacio público transregionales para una justicia global.

\section{Bibliografía}

Arabella Advisors (2018) Understanding and Confronting the Prison-Industrial Complex: An Overview for Philanthropists, October 2018. (https://www.arabellaadvisors.com/wp-content/uploads/2018/) 
Alvarez, Sonia E. (1993) “'Deeping' Democracy: Popular Movement Networks, Constitutional Reform, and Radical Urban Regimes in Contemporary Brazil", in Fisher, R. and Kling, J., (eds.), Moblizing the Community: Local Politics in the Era of the Global City, London, SAGE Publications.

Avritzer, Leonardo (2002) Democracy and the Public Space in Latin America, Princeton University Press.

- - (2009) Participatory Institutions in Democratic Brazil, Washington, D. C. Woodrow Wilson Centre Press.

Avritzer, Leonardo (2005) "Modes of Democratic Deliberation: Participatory Budgeting in Brazil", in Santos, Boaventura de Sousa, (ed.), Democratizing Democracy: Beyond the Liberal Democratic Canon, London, Verso.

_-_-(2006) "New public spheres in Brazil." International Journal of Urban Regional Research, vol. 30, no. 3, pp. 623-37.

Brown, Wendy (2015) Undoing the Demos: Neoliberalism's Stealth Revolution, Zone Books.

Baiocchi, Gianpaolo, Patrick Heller, and Marcelo K. Silva (2011). Bootstrapping Democracy: Transforming Local Governance and Civil Society in Brazil, Stanford University Press.

Beck, Ulrich (2002) Macht und Gegenmacht im globalen Zeitalter: Neue weltpolitische Ökonomie, Suhrkamp Verlag, Frankfurt am Main (in Japanese version).

Bullard, Nicola（2012）. Global South", Helmut K. Anheier and Mark Juergensmeyer (eds.) Encyclopedia of Global Studies, Sage, pp.724-727.

Cameron, Maxwell A. and Kenneth E. Sharpe ( eds. )(2010). Latin America's Left Turns: Politics, Policies \& Trajectories of Change, Lynne Rienner Publishers.

Cepeda Carolina (2016) "How to hate neoliberalism but love each other: a Latin American grassroots guide", The Conversation, December 5.

Cornwall A. and Gaventa, J. (2000). "From Users and Choosers to Makers and Shapers: Repositioning Participation Social Policy", IDS Bulletin, 31(4), 50-62.

Cox, Robert W. (1994) "The Crisis in World Order and the Challenge to International Organization", in Cooperation and Conflict, 29 (2).

Cruz, José Miguel and Brian Fonseca_(2021) "How Transnational Crime Is Mutating in the Age of COVID-19 in Latin America", Americas Quarterly, JANUARY 26.

Cypher, James (2014) “Energy Privatized: The Ultimate Neoliberal Triumph,” NACLA, June,11.

Cypher, James and James Dietz (2009) The process of economic development, $3^{\text {rd }}$ ed.London, Routledge.

Cypher, J.M. \& Delgado-Wise, R. (2010) Mexico's economic dilemma: The developmental failure of neoliberalism, Lanham, MD: Rowman \& Littlefield.

Davis, Mike (2020) The Coronavirus Crisis Is a Monster Fueled by Capitalism - In These Times, March 24, 2020 ( https://inthesetimes.com/article/coronavirus-crisis.) 
De la Torre, Carlos (2010). Populist Seduction in Latin America, Center for International Studies, Ohio University.

Falk, Richard（1995） On Humane Governance: Toward a New Global Politics, The World Models Project Report of the Global Civilization Initiative, Pennsylvania State University Press.

- (2016) Power Shift: On the New Global Order, London ,Zed Books.

Fisher, William F. and Ponniah, Thomas, eds.(2003), Another World is Possible: Popular Alteernative to Globalization at the World Social Forum, London and New York, Zed Books.

Flores- Macías, Gustavo A. (2012). After Neoliberalism? : The Left and Economic Reforms in Latin America, Oxford University Press.

Gaventa, John (2010) "Foreward", in Thompson,Lisa and Chris Tapscott (eds.).Citizenship and Social Moements: Perspective from Global South, Zed Books.

Gill, Stephen (1995), “Globalization, Market Civilization, and Disciplinary Neoliberalism”, Millennium: Journal of International Studies 24.3, pp.399-423.

Giroux, Henry A.(2021) "The COVID-19 Pandemic Is Exposing the Plague of Neoliberalism", Truthout. (https://truthout.org/articles/the-covid-19-pandemic-isexposing-the-plague-of-neoliberalism/ : 2021/03/15.

Gret, Marion and Sintomer (2005). The Porto Alegre Experiment : Learning Lessons for Better Democracy, London and New York, Zed Books.

Grugel Jean and Pía Riggirozzi ( eds.) （2009） .Governance After Neoliberalism in Latin America, Palgrave Macmillan.

Harvey, David (2005) A Brief History of Neoliberalism, Oxford. Oxford University Press. (2009) Cosmopolitanism and the Geographies of Freedom, Columbia University Press.

- (2010) The Enigma of Capital and the Crises of Capitalism, Profile Books.

- (2012) Rebel Cities: From the Right to the City to the Urban Revolution, Verso.

- (2014) Seventeen Contradictions and the End of Capitalism, Profile Books.

— (2016)Neoliberalism Is a Political Project : AN INTERVIEW WITH

07.23.2016 (ABOUT THE INTERVIEWER: Bjarke Skærlund Risager is a PhD

fellow in the Department of Philosophy and History of Ideas at Aarhus University. )

(https://www.jacobinmag.com/2016/07/david-harvey-neoliberalism-capitalism-labor-crisisresistance/ ) (2021/03/15)

- (2020) Anti-Capitalist Politics in the Time of COVID-19, 2020/03/20 .

(https://jacobinmag.com/2020/03/david-harvey-coronavirus)

Held, David (1995) Democracy and the Global Order: from the Modern State to Cosmopoli- 
tan Governance, Polity Press.

- (2000) A globalizing world?: Culture, economics, politics, The Open University.

Heller, Patrick (2001) "Moving the State: The Politics of Democratic Decentralization in Kerala, South Africa and Porto Alegre", Politics and Society, 29 (1).

Herkenrath, Mark (ed.) (2007) The Regional and Local Shaping of World Society, The World Society Foundation, Zurich (A series edited by World Society Foundation, World Society Studies, Volume II , Zurich).

- - (2007b) Civil Society: Local and Regional Responses to Global Challenges, (A series edited by World Society Foundation, World Society Studies, Volume I , Zurich).

Hirst, Paul and Thompson, Grahame (1996), Globalization in Question, the International Economy and the Possibilities of Governance, Polity Press.

Huber, Evelyne and John D. Stephens (2012). Democracy and the Left: Social Policy and Inequality in Latin America, The University of Chicago Press.

Kellogg, Paul 2007, "Regional Integration in Latin America: Dawn of an Alternative to Neoliberalism”, New Political Science, Volume 29, Number 2, June.

Klein, Naomi (2017) No Is Not Enough: Resisting Trump's Shock Politics and Winning the World We Need, Haymarket Books.

Laval, Chrisitian (2007) L'Homme économique —Essai sur les raciness du néoliberalisme, Gallimard.

Llorente, Bernarda (2020) "Boaventura de Sousa Santos: ¿ Cuáles son las tres salidas a la COVID-19 ?" Cubadebate, 2020/12/07.

(www.cubadebate.cu/especiales/2020/12/07/boaventura-de )

Lordon, Féderic (2010) Capitalisme, désir et servitude: Marx et Apinoza, La Fabrique éditions

Lyon, David (2001) Surveillance Society: Monitoring Every Life, Open University Press.

McGrew, Anthony (2000) "Power shift from national government to global governance?", in David Held(2000) A globalizing world?: Culture, economics, politics, The Open University.

Mittelman, James H. (2000). The Globalization Syndrome: Transformation and Resistance. Princeton: Princeton University Press.

Neamtan, Nancy（2002）."The Social and Solidarity Economy: Towards an 'Alternative'Globalisation", Paper prepared for the symposium Citizenship and Globalization: Exploring Participation and Democracy in a Global Context, June 1416,2002.

Roberts, Michael (2019) "The top 1\% own 45\% of all global personal wealth; $10 \%$ own $82 \%$; the bottom $50 \%$ own less than $1 \% ", A L A l, 25 / 10 / 2019$,

(https://www.alainet.org/en/articulo/202869)

Robinson, William I. (2004) A Theory of Global Capitalism, Johns Hopkins University Press. 
- (2013) "New Global Capitalism and the War on Immigrations", Truthout, September 13, 2013.

- (2014).Global Capitalism and the Crisis of Humanity, Cambridge University Press.

- (2017) "Trumpism and the New Economy", América Latina en movimiento, 28/07/2017,( https://www.alainet.org/es/node/187154.)

- (2018) "Global Capitalism, Migrant Labor, and the struggle for Social Justice", in INTO THE TEMPEST; ESSAY ON THE NEW GLOBAL CAPITALISM, Haymarket Books, Chicago, Illinois, pp.123-141.

- (2020a) The Global Police State, Pluto Press.

- (2020b) "Beyond the Economic Chaos of Coronavirus Is a Global War Economy", Truthout, March 23.

— (2020c) “GLOBAL CAPITALIST CRISIS DEADLIER THAN CORONAVIRUS (PART I) ", ARENA ONLINE, 14 APR 2020,

(https://arena.org.au/global-capitalist-crisis-deadlier-than-coronavirus-part-i/.)

-(2020d) “GLOBAL CAPITALIST CRISIS DEADLIER THAN CORONAVIRUS (PART II) ”, ARENA ONLINE, 21 APR 2020,

(https://arena.org.au/global-capitalist-crisis-deadlier-than-coronavirus-part-ii/.)

-(2020e)“GLOBAL CAPITALIST CRISIS DEADLIER THAN CORONAVIRUS (PART III) " ARENA ONLINE, 28 APR 2020, (https://arena.org.au/global-capitalist-crisis-deadlierthan-coronavirus-part-iii/.)

Sader, Emir (2011). The New Model: Paths of the Latin American Left, London, Verso Books.

Sandoval, Juan Manuel (2017) La Frontera Mexico Estados Unidos, National Institute of Anthropology and History, Mexico City.

Santos, Boaventura de Sousa (1998). "Participatory Budgeting in Porto Alegre: Toward a redistributive democracy." Politics and Society, vol. 4, pp. 461-510.

Santos, Boaventura de Sousa (ed.) (2005). Democratizing Democracy: Beyond the Liberal Democratic Canon, London, Verso.

- - (2006). The Rise of the Global Left: The World Social Forum and Beyond, Zed Books.

Sassen, Saskia (2014) Expulsion: Brutality and Complexity in the Global Economy, The Belknap Press of Harvard University Press.

Sen, Amartya (1999) Development as Freedom, New York: Oxford University Press.

Singer, Peter W. (2003) Corporate Warriors: The Rise of the Privatized Military Industry, Cornell University Press.

Söderbaum, Fredrik (2003), "Introduction: Theories of New Regionalism", in Söderbaum, Fredrik and Shaw, Timothy M. (eds.), Theories of New Regionalism, Palgrave.

Tavares, Rodrigo and Schulz, Michael (2006) "Measuring the Impact of Regional Organisations 
on Peace Building" in De Lombaerde, Philippe (ed.), Assessment and Measurement of Regional Integration ,London: Routledge.

Thompson, Lisa and Chris Tapscott (eds.) (2010) Citizenship and Social Movements: Perspectives from the Global South, Zed Books.

Weyland, Kurt, Raul L. Madrid, and Wendy Hunter eds. (2010) Leftist Governments in Latin America: Successes and Shortcomings. Cambridge University Press. 